\title{
OPEN A novel and facile green synthesis method to prepare LDH/MOF nanocomposite for removal of $\mathrm{Cd}(\mathrm{II})$ and $\mathrm{Pb}(\mathrm{II})$
}

\author{
Roozbeh Soltani ${ }^{1}$, Rasool Pelalak ${ }^{2,3}$, Mahboubeh Pishnamazi ${ }^{2,4}$, Azam Marjani ${ }^{5,6 \square}$, \\ Ahmad B. Albadarin ${ }^{7}$, Shaheen M. Sarkar ${ }^{7}$ \& Saeed Shirazian ${ }^{2,3,8}$
}

To date, many nanoadsorbents have been developed and used to eliminate heavy metal contamination, however, one of the challenges ahead is the preparation of adsorbents from processes in which toxic organic solvents are used in the least possible amount. Herein, we have developed a new carboxylic acid-functionalized layered double hydroxide/metal-organic framework nanocomposite (LDH/MOF NC) using a simple, effective, and green in situ method. UiO-66-(Zr)$(\mathrm{COOH})_{2}$ MOF nanocrystals were grown uniformly over the whole surface of $\mathrm{COOH}$-functionalized $\mathrm{Ni}_{50} \mathrm{Co}_{50}$-LDH ultrathin nanosheets in a green water system under a normal solvothermal condition at $100^{\circ} \mathrm{C}$. The synthesized LDH/MOF NC was used as a potential adsorbent for removal of toxic $\mathrm{Cd}$ (II) and $\mathrm{Pb}$ (II) from water and the influence of important factors on the adsorption process was monitored. Various non-linear isotherm and kinetic models were used to find plausible mechanisms involved in the adsorption, and it was found that the Langmuir and pseudo-first-order models show the best agreement with isotherm and kinetic data, respectively. The calculated maximum adsorption capacities of $\mathrm{Cd}$ (II) and $\mathrm{Pb}$ (II) by the LDH/MOF NC were found to be 415.3 and $301.4 \mathrm{mg} \mathrm{g}^{-1}$, respectively, based on the Langmuir model $(\mathrm{pH}=5.0$, adsorbent dose $=0.02 \mathrm{~g}$, solution volume $=20 \mathrm{~mL}$, contact time $=120 \mathrm{~min}$, temperature $=25^{\circ} \mathrm{C}$, shaking speed $200 \mathrm{rpm}$ ).

The escalating level of heavy metal released in the aquatic environment is a cause of widespread public health problems associated with environmental pollution, especially water contamination. Heavy metals released through various anthropogenic activities such as leather, cosmetics, electronics, and battery manufacturing industries are one of the primary sources of this worsening environmental pollution ${ }^{1,2}$. In order to decrease the negative impact of heavy metals on the environment, the level of heavy metal pollution in the environment must be minimized. The challenge is to develop appropriate removal techniques for the remediation of heavy metals ${ }^{3}$. Adsorption technique is considered as an energetically efficient, simple, and economical strategy for heavy metals removal ${ }^{4-9}$. For this adsorption-based process to be efficient, it is essential to have porous adsorbents at the nano-/microscale with acceptable adsorption performance ${ }^{10-14}$. Over the past decade, metal-organic frameworks (MOFs), an interesting class of hybrid crystalline nanoporous substances, have quickly developed into one of the most exciting fields of research in material science, physics, chemistry, and interdisciplinary fields ${ }^{15,16}$. The physicochemical properties of MOFs permit their structural features to be finely tuned-based on reticular synthesis-over an extremely broad range. Indeed, several recent works claimed that these materials could be utilized as an ideal platform for the adsorption of pollutants like heavy metals ${ }^{17-20}$.

To date, heavy metal adsorption performance of various kinds of MOFs has been evaluated, primarily on the criteria of (1) a large heavy metal adsorption capacity though this is not necessarily of primary importance to effectively remove heavy metals under practical conditions, and (2) synthesis of a new MOF with a novel porous

\footnotetext{
${ }^{1}$ Department of Chemistry, Arak Branch, Islamic Azad University, Arak, Iran. ${ }^{2}$ Institute of Research and Development, Duy Tan University, Da Nang 550000, Vietnam. ${ }^{3}$ Faculty of Environmental and Chemical Engineering, Duy Tan University, Da Nang 550000, Vietnam. ${ }^{4}$ Faculty of Pharmacy, Duy Tan University, Da Nang 550000, Vietnam. ${ }^{5}$ Department for Management of Science and Technology Development, Ton Duc Thang University, Ho Chi Minh City, Vietnam. ${ }^{6}$ Faculty of Applied Sciences, Ton Duc Thang University, Ho Chi Minh City, Vietnam. ${ }^{7}$ Department of Chemical Sciences, Bernal Institute, University of Limerick, Limerick, Ireland. ${ }^{8}$ Laboratory of Computational Modeling of Drugs, South Ural State University, 76 Lenin prospekt, Chelyabinsk 454080, Russia. ${ }^{\boxplus}$ email: azam.marjani@tdtu.edu.vn
} 
structure though it is questionable whether the construction of a new adsorbent does not necessarily promise an adsorbent with acceptable performance for practical use. This evaluation strategy led researchers and scientists to design and development numerous targeted MOFs combining highly specific surface area and the existence of specific organic functional groups as adsorption sites that can effectively capture heavy metal anions/cations. On the contrary, a potential limitation to the use of a large number of MOFs for adsorption applications is the sensitivity of them to moisture and aqueous media, as most of them are prone to hydrolysis, which is associated with structural degradation ${ }^{17,19,20}$. Accordingly, another important challenge in using MOFs as heavy metals adsorbents is the synthesis of water-resistant MOFs. Further, little attention has been paid to the recovery and regeneration of such powder-type adsorbents. Soltani et al. ${ }^{20}$ reported that the chemical attachment of MOF nanocrystals (BMZIF20) on ultrathin sheets of Ni-Co layered double hydroxide $\left(\mathrm{Ni}_{50} \mathrm{Co}_{50}-\mathrm{LDH}\right)$ by in situ synthesis protocol could solve the problem of separating fine MOF particles from the aqueous environment. Under this circumstance, the fine MOF particles (with nanometer size) are uniformly attached to the LDH sheets (with micrometer size) and easily separated from the aqueous environment by centrifugation. Although this strategy is a smart option to solve the problem of separation of nanometer-sized MOF crystals from aqueous solutions, the problem of using the toxic methanol solvent in the synthesis process of MOF and its LDH hierarchical nanocomposite (LDH/MOF NC) remains a challenge. Consequently, it is of great importance to choose suitable components for the preparation of $\mathrm{LDH} / \mathrm{MOF} \mathrm{NC}$ as an applicable adsorbent where both $\mathrm{LDH}$ and MOF are prepared via a facile, economic, and environmentally friendly method. $\mathrm{Ni}_{50} \mathrm{Co}_{50}-\mathrm{LDH}$ is a $2 \mathrm{D}$-ultrathin material that could be an excellent option for use as a scaffold for the growth of MOF crystals due to its extended ultrathin sheets, facile production, large-scale synthesis route, and most importantly, use of a non-toxic waterethylene glycol (EG) solvent mixture instead of conventional toxic organic solvents ${ }^{20,21}$. Moreover, according to the literature ${ }^{22}$, LDH materials themselves possess the ability to adsorb heavy metals, which can help increase the adsorption performance of heavy metals by the LDH/MOF NC.

Recently, Yang et al. ${ }^{23}$ reported a new water-stable MOF labeled as UiO-66( $\left.\mathrm{Zr}\right)-(\mathrm{COOH})_{2}$ which can be prepared through a facile room-temperature synthesis route. It is our view that, compared to other MOFs, this MOF would be the best choice to combine with $\mathrm{Ni}_{50} \mathrm{Co}_{50}-\mathrm{LDH}$ to produce a hybrid LDH/MOF NC from the environmental point of view, economic justification, synthesis method, and adsorbent structure.

To meet the above criteria, we report for the first time a novel $\mathrm{Ni}_{50} \mathrm{Co}_{50}-\mathrm{LDH}-\mathrm{COOH} / \mathrm{UiO}-66(\mathrm{Zr})-(\mathrm{COOH})_{2}$ nanocomposite (LDH/MOF NC) as a promising water-stable adsorbent. Its synthesis especially emphasizes.

1. The nature of the solvent: whereas most MOFs and LDHs are synthesized in toxic organic solvents such as DMF, DMSO, methanol, etc., only water was used. In the case of MOF, water has been used both for the preparation and activation process. In the case of $\mathrm{LDH}$, water and $\mathrm{EG}$ were used as a solvent mixture. In terms of environmental, economic, and recovery issues, the use of water as a green solvent is a great advantage over organic solvents.

2. The scale: in the case of MOF, a facile ambient-pressure process and a low-cost reaction environment (roundbottom glass flask) was developed, permitting easily scale-up of the production. In the case of LDH, a facile water-EG reflux system was used for large-scale preparation of ultrathin LDH sheets.

3. The introduction of pendent adsorption cites (functional groups) decorating the pores of MOF: free $-\mathrm{COOH}$ groups display strong adsorption affinity toward heavy metal cations.

4. Strong covalent bond (chemical attachment) between MOF and LDH surface in the hybrid LDH/MOF NC structure: by implementing a chemical surface functionalization method via attaching -COOH groups on the LDH surface (LDH-COOH), MOF crystals can readily grow on the LDH-COOH surface (Scheme 1). By implementing this synthetic strategy, in addition to being able to use the adsorption properties of both components, we can simplify the separation process (centrifugation) by increasing the particle size of the adsorbent.

\section{Results and discussion}

Synthesis of LDH/MOF NC. From the point of view of green chemistry, the utilization of safer solvents is important in the preparation of chemical structures. Therefore, in this work, an attempt has been made not to use hazardous organic solvents in the construction of both MOF and LDH, as well as their nanocomposite. Here, for the first time, a synthesis route for the preparation of the LDH/MOF NC has been developed in a green, simple, and functional way, and the synthesized nanocomposite has been used as an adsorbent to remove toxic $\mathrm{Cd}(\mathrm{II})$ and $\mathrm{Pb}$ (II) heavy metals.

Before in situ growth of MOF crystals on the LDH surface, the surface of LDH nanosheets was functionalized with pyromellitic acid molecules (Scheme 1) to enhance the degree of grafting and enabling coordination bonding between secondary building units in MOF and carboxylate functional groups on the LDH surface (pyromellitic acid molecules). Under this circumstance, $\mathrm{UiO}-66(\mathrm{Zr})-(\mathrm{COOH})_{2}$ nanocrystals begin to grow on the surface of $\mathrm{Ni}_{50} \mathrm{Co}_{50}-\mathrm{LDH}-\mathrm{COOH}$. From the point of view of the formation of a stable nanocomposite structure, surface modification of the LDH nanosheets with carboxylic acid groups is important because it causes a strong chemical interaction between the MOF nanocrystals and the ultrathin nanosheets of LDH and, accordingly, keeps the two components of the nanocomposite together.

Structure characterization of the samples. In order to study the physicochemical properties of the samples, as well as their structure, the following analyses were used: powder X-ray diffraction (PXRD), Fourier transform infrared (FT-IR), Field emission scanning electron microscopy-energy dispersive X-ray (FESEMEDX), and $\mathrm{N}_{2}$ adsorption-desorption isotherm measurements. Flame atomic absorption spectroscopy (FAAS) analysis was also used to determine the concentration of heavy metals in the aqueous medium. 

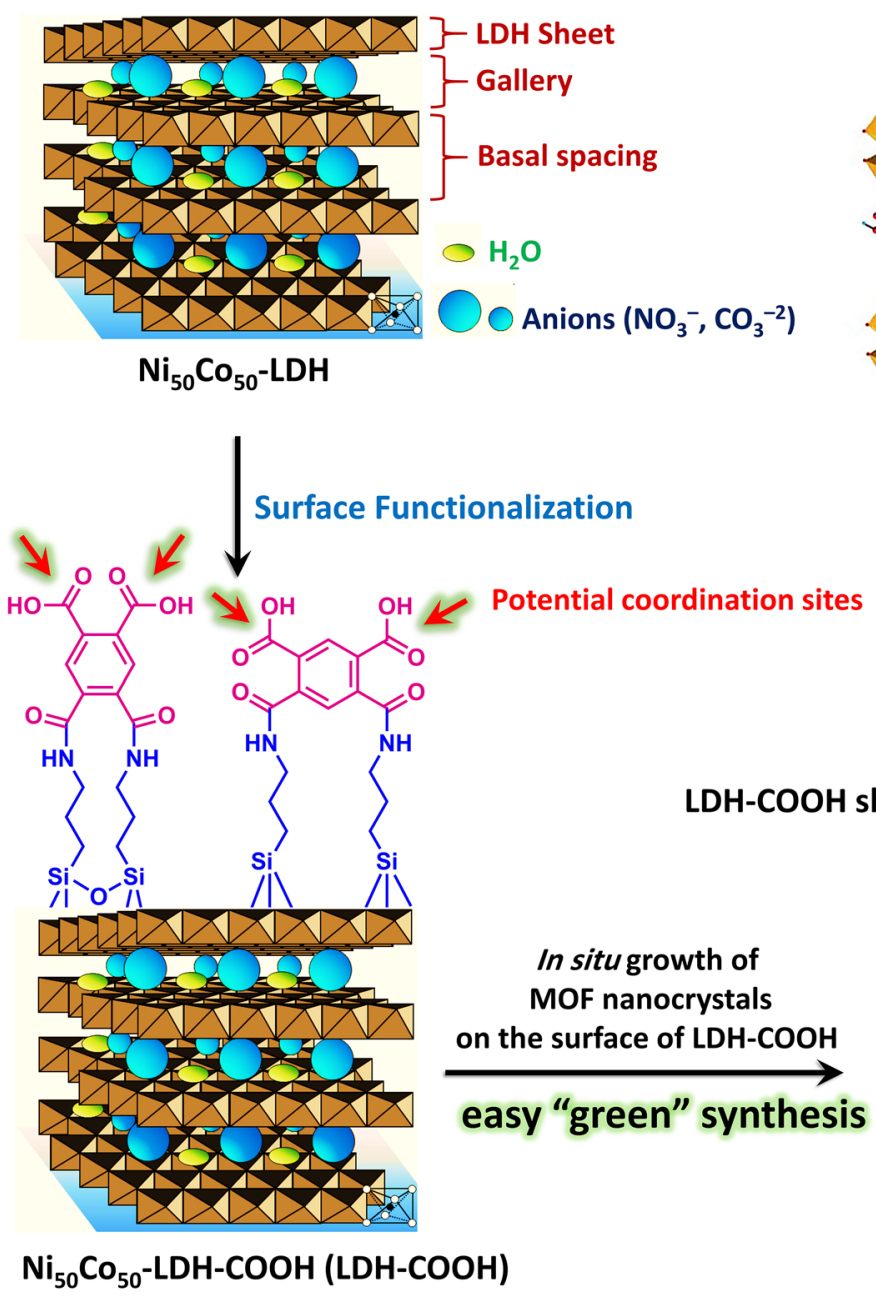

Octahedral cage

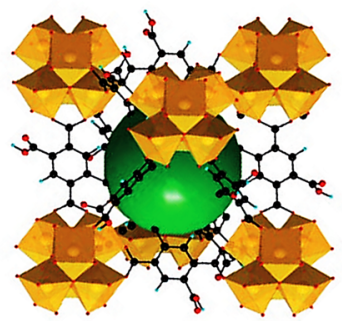

Crystalline structure of UiO-66(Zr)-(COOH $)_{2}$
Tetrahedral cage

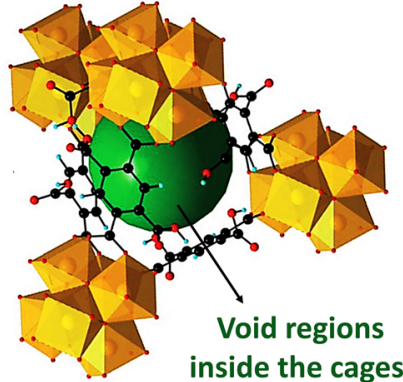

inside the cages

Zr polyhedral

C black

0 red

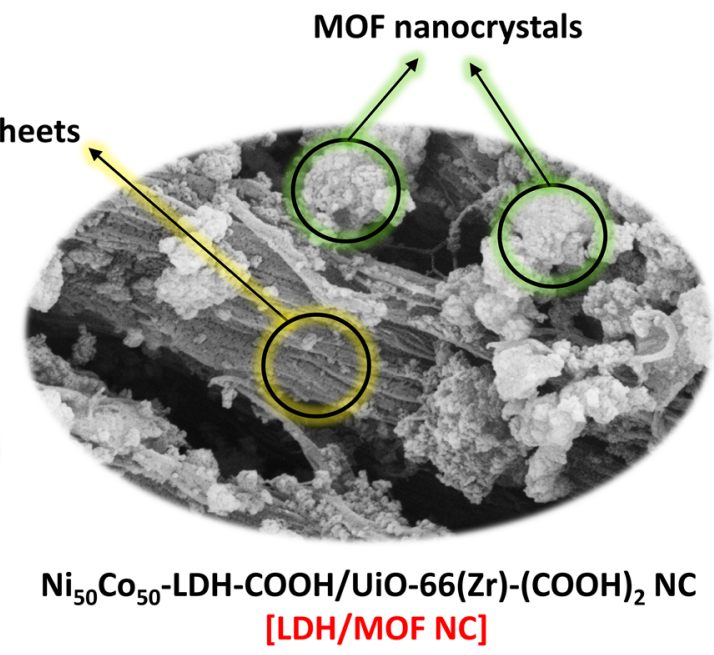

Scheme 1. The overall strategy for the synthesis of $\mathrm{Ni}_{50} \mathrm{Co}_{50}-\mathrm{LDH}-\mathrm{COOH} / \mathrm{UiO}-66(\mathrm{Zr})-(\mathrm{COOH})_{2} \mathrm{NC}[\mathrm{LDH} /$ MOF NC].

XRD characterization. As shown in Fig. 1, the XRD profiles of $\mathrm{Ni}_{50} \mathrm{Co}_{50}-\mathrm{LDH}$ and $\mathrm{UiO}-66(\mathrm{Zr})-(\mathrm{COOH})_{2}$ show a similar pattern to the same samples synthesized in previous works which express the successful synthesis of these samples ${ }^{18,20,21,23-25}$. The PXRD pattern of the composite shows that peaks representing both the LDH phase and MOF phase are still present in the composite, indicating the simultaneous presence of both phases in the composite structure and, in other words, the growth of MOF crystals on the LDH sheets. Compared to pure MOF, the crystalline peaks in the composite are less intense due to the simultaneous presence of two phases of $\mathrm{LDH}$ (with low crystallinity) and MOF (with high crystallinity) in the composite structure.

FT-IR measurement. FT-IR spectra of the samples are given in Fig. 1. The characteristic absorption bands related to the functional groups and chemical structure of the pure LDH and MOF were observed and are in agreement with the literature ${ }^{18,20,21,25}$. After surface functionalization of LDH, the presence of new absorption bands at $1572 \mathrm{~cm}^{-1}$ and $1491 \mathrm{~cm}^{-1}$ was observed which are attributed to the aromatic structure of the pyromellitic acid molecules. Also, a strong broad absorption band in the range of $3000-3600 \mathrm{~cm}^{-1}$ region is due to the hydrogen bonding between carboxyl groups. These observations are indicative of successful surface modification of $\mathrm{LDH}$ with carboxylic acids groups ( $\mathrm{LDH}-\mathrm{COOH})$. In the FT-IR spectrum of the composite sample, characteristic absorption bands of both $\mathrm{LDH}$ and $\mathrm{MOF}$ are observed, indicating the simultaneous presence of both phases in the composite structure. Absorption bands and corresponding functional groups for each sample are listed in Table 1.

FESEM images and EDX mapping analyses. Figure 2 shows the FESEM figures of the samples. Figure 2 (first row) clearly reveals the micrographs of UiO-66(Zr)- $(\mathrm{COOH})_{2}$ nanoparticle. Also, as shown in Fig. 2 (second row), $\mathrm{Ni}_{50} \mathrm{Co}_{50}$ - $\mathrm{LDH}$ material has an ultrathin sheet-like morphology with a smooth surface. The FESEM images taken after in situ growth of MOF nanocrystals on the surface of LDH sheets clearly show the presence of MOF nanoparticles on the LDH sheets which are uniformly distributed on the sheets (Fig. 2, third row), indicating successful growth of $\mathrm{UiO}-66(\mathrm{Zr})-(\mathrm{COOH})_{2}$ nanocrystals on the $\mathrm{Ni}_{50} \mathrm{Co}_{50}-\mathrm{LDH}$ ultrathin nanosheets. 

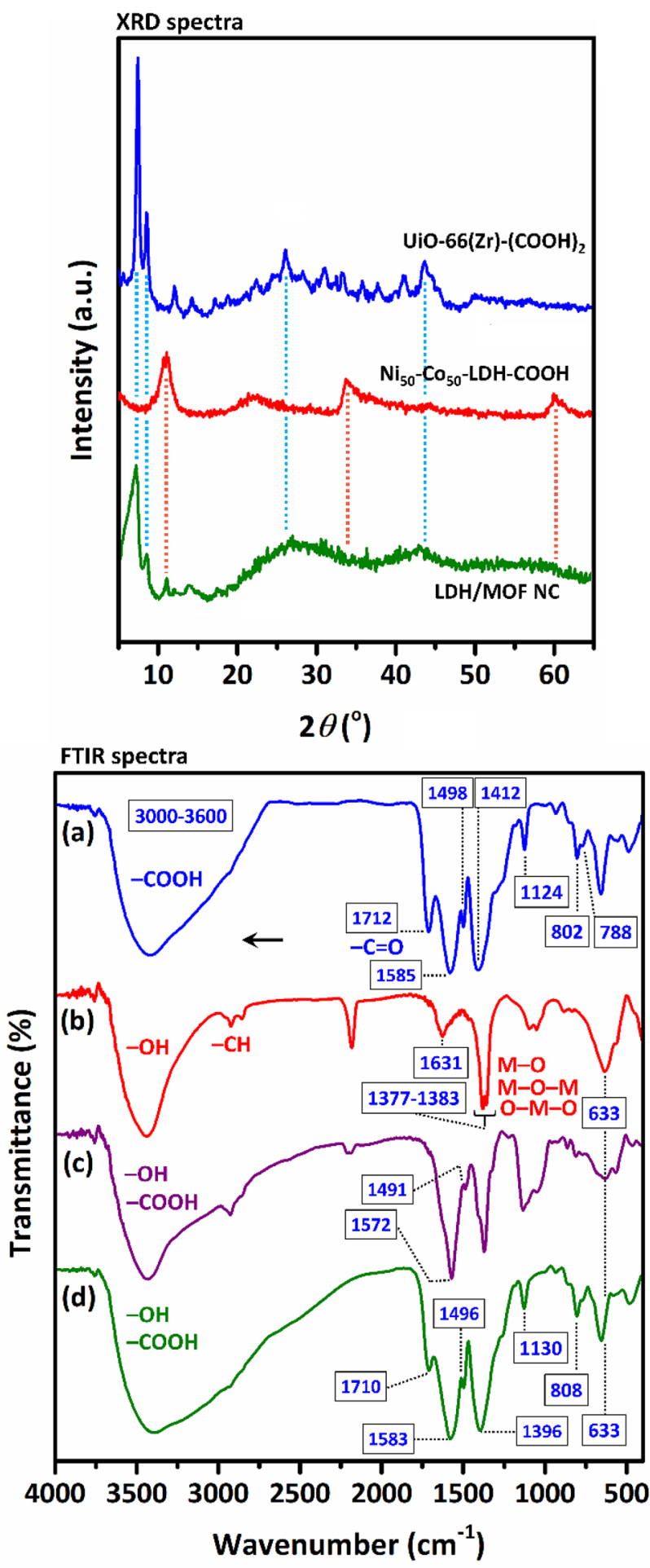

Figure 1. XRD and FT-IR spectra of the samples: (a) pure UiO-66(Zr)-(COOH $)_{2}(\mathrm{MOF}),(\mathbf{b})$ pure $\mathrm{Ni}_{50} \mathrm{Co}_{50^{-}}$ $\mathrm{LDH},(\mathbf{c}) \mathrm{Ni}_{50} \mathrm{Co}_{50}-\mathrm{LDH}-\mathrm{COOH}(\mathrm{LDH}-\mathrm{COOH})$, and (d) LDH/MOF NC.

The images plainly demonstrate the role of $\mathrm{LDH}$ sheets as a scaffold for the in situ formation and growth of MOF nanoparticles.

FESEM-EDX mapping of LDH/MOF NC and the corresponding structural elements are shown in Fig. 3. The images reveal that $\mathrm{LDH} / \mathrm{MOF}$ NC possesses a uniform surface structure with a homogeneous distribution of elements, implying that MOF nanocrystals are uniformly distributed on the LDH ultrathin sheets. Also, the EDX peaks corresponding to the structural elements of composite $(\mathrm{Co}, \mathrm{Ni}, \mathrm{O}, \mathrm{N}, \mathrm{C}, \mathrm{Si}$, and $\mathrm{Zr}$ ) are depicted in EDX spectra (Fig. 3). The presence of nitrogen atom in the structure of the composite is due to the presence of 


\begin{tabular}{|c|c|c|c|c|}
\hline \multicolumn{5}{|c|}{ Bands $\left(\mathrm{cm}^{-1}\right)$} \\
\hline MOF & LDH & LDH-COOH & LDH/MOF NC & Vibrational mode \\
\hline 788 & & 771 & 788 & $\gamma \mathrm{CH}$ in aromatic rings \\
\hline 802 & & 801 & 808 & Vibrations of phenyl rings \\
\hline 852 & & 860 & 854 & $\delta \mathrm{CO}\left(\mathrm{COO}^{-}\right)$ \\
\hline 1124 & & 1133 & 1130 & $\delta \mathrm{CH}$ in aromatic rings \\
\hline 1412 & & & 1396 & $\vartheta_{\mathrm{s}} \mathrm{CO}\left(\mathrm{COO}^{-}\right)$in coordinated carboxylic acids \\
\hline 1498 & & 1491 & 1496 & Vibrations of phenyl rings \\
\hline 1585 & & & 1583 & $\vartheta_{\mathrm{as}} \mathrm{CO}\left(\mathrm{COO}^{-}\right)$in coordinated carboxylic acids \\
\hline 1712 & & 1572 & 1710 & $\vartheta_{\mathrm{as}} \mathrm{CO}\left(\mathrm{COO}^{-}\right)$in free carboxylic acids (pendent) \\
\hline \multirow[t]{6}{*}{$3000-3600$} & & $3000-3600$ & $3000-3600$ & Crystalline water and acidic $\mathrm{OH}$ of carboxylic groups \\
\hline & 633 & 636 & $\sim 633(\mathrm{OL})$ & $\vartheta \mathrm{M}-\mathrm{O}, \mathrm{M}-\mathrm{O}-\mathrm{M}$ and $\mathrm{O}-\mathrm{M}-\mathrm{O} ; \mathrm{M}=\mathrm{Co}$ and $\mathrm{Ni}$ \\
\hline & $1377-1383$ & $1371-1398$ & $\sim 1377-1383(\mathrm{OL})$ & Vibration of interlayer $\mathrm{NO}_{3}^{-}$and $\mathrm{CO}_{3}^{2-}$ anions \\
\hline & 1631 & 1630 & $\sim 1631(\mathrm{OL})$ & $\delta \mathrm{OH}$ in water molecules \\
\hline & $2856-2923$ & $2871-2929$ & $\sim 2856-2923(\mathrm{OL})$ & $\vartheta_{\mathrm{s}} \mathrm{CH}$ vibration (trace amount of EG) \\
\hline & 3446 & $\sim 3445(\mathrm{OL})$ & $\sim 3446(\mathrm{OL})$ & $\vartheta \mathrm{M}-\mathrm{OH}$ vibration and interlayer water molecules \\
\hline
\end{tabular}

Table 1. Absorption bands observed in FT-IR spectra of the samples (OL overlapped).

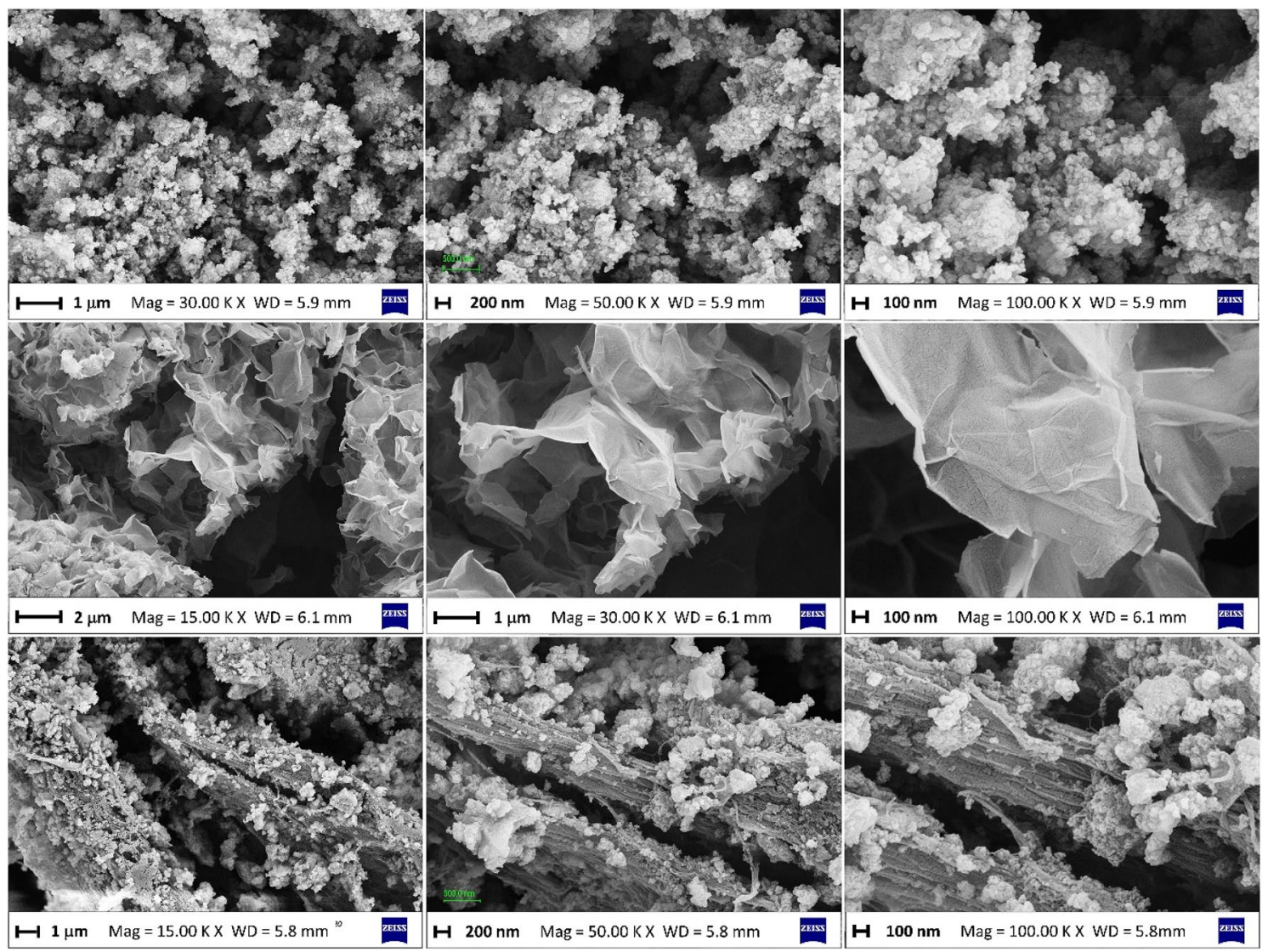

Figure 2. FESEM images of the pure $\mathrm{UiO}-66(\mathrm{Zr})-(\mathrm{COOH})_{2}$ (first row), pure $\mathrm{Ni}_{50} \mathrm{Co}_{50}-\mathrm{LDH}$ (second row), and LDH/MOF NC (third row).

(1) silane coupling agent (amine group in APTES molecule) grafted on the LDH surface as well as (2) interlayer nitrate anions (gallery anion) in LDH material (Scheme 1). Also, the presence of Si atom is due to the presence of the silane coupling agent grafted on the surface of LDH sheets (Scheme 1).

$\mathbf{N}_{2}$ adsorption-desorption isotherms. The adsorption-desorption isotherms of the samples were measured with $\mathrm{N}_{2}$ gas at $77 \mathrm{~K}$ to study their porosity and texture properties. The obtained results are tabulated in Table 2 and corresponding adsorption-desorption isotherms are shown in Fig. 4. The UiO-66( $\mathrm{Zr})-(\mathrm{COOH})_{2}$ 

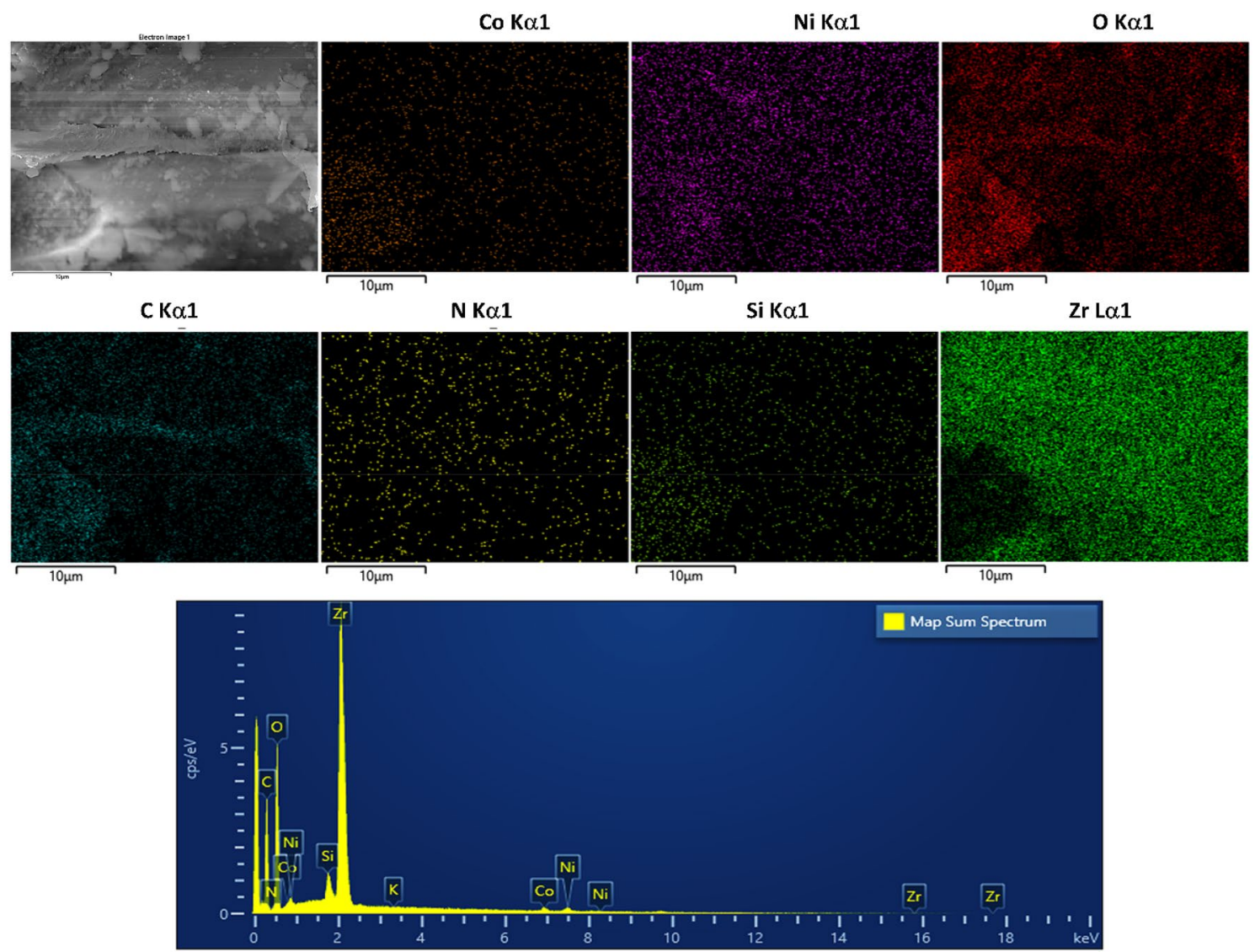

Figure 3. FESEM-EDX mapping images of $\mathrm{LDH} / \mathrm{MOF} \mathrm{NC}$ and the corresponding elements (Co, Ni, $\mathrm{O}, \mathrm{C}, \mathrm{N}$, $\mathrm{Si}$, and $\mathrm{Zr}$ ) and its EDX spectrum.

\begin{tabular}{|c|c|c|c|c|c|c|}
\hline \multirow[b]{2}{*}{ Sample } & \multicolumn{4}{|c|}{ Surface area $\left(\mathrm{m}^{2} \mathrm{~g}^{-1}\right)$} & \multirow[b]{2}{*}{$\mathrm{PV}\left(\mathrm{cm}^{3} \mathrm{~g}^{-1}\right)$} & \multirow[b]{2}{*}{$\operatorname{APD}(\mathbf{n m})$} \\
\hline & $S_{\text {BET }}$ & $S_{\text {Langmuir }}$ & $S_{\text {Micro }}$ & $S_{\text {Meso }}$ & & \\
\hline $\mathrm{UiO}-66(\mathrm{Zr})-(\mathrm{COOH})_{2}$ & 130 & 122 & 120 & 10 & 0.43 & 1.2 \\
\hline $\mathrm{Ni}_{50}-\mathrm{Co}_{50}-\mathrm{LDH}-\mathrm{COOH}$ & 27 & 25 & 15 & 12 & 0.23 & $2.4-6.1$ \\
\hline LDH/MOF NC & 41 & 39 & 32 & 9 & 0.13 & 1.9 \\
\hline
\end{tabular}

Table 2. The results of BET and BJH analyses for the synthesized samples $\left(S_{\mathrm{BET}}, S_{\text {Langmuir }}\right.$, and $S_{\text {Micro }}$ represent surface area according to the BET, Langmuir, and t-plot method, respectively. $S_{\text {Meso }}$ and $S_{\text {Micro }}$ demonstrate micropore surface area and mesopore surface area, respectively: $S_{\text {Meso }}=S_{\mathrm{BET}}-S_{\text {Micro }}$ PV and APD are pore volume and average pore diameters).
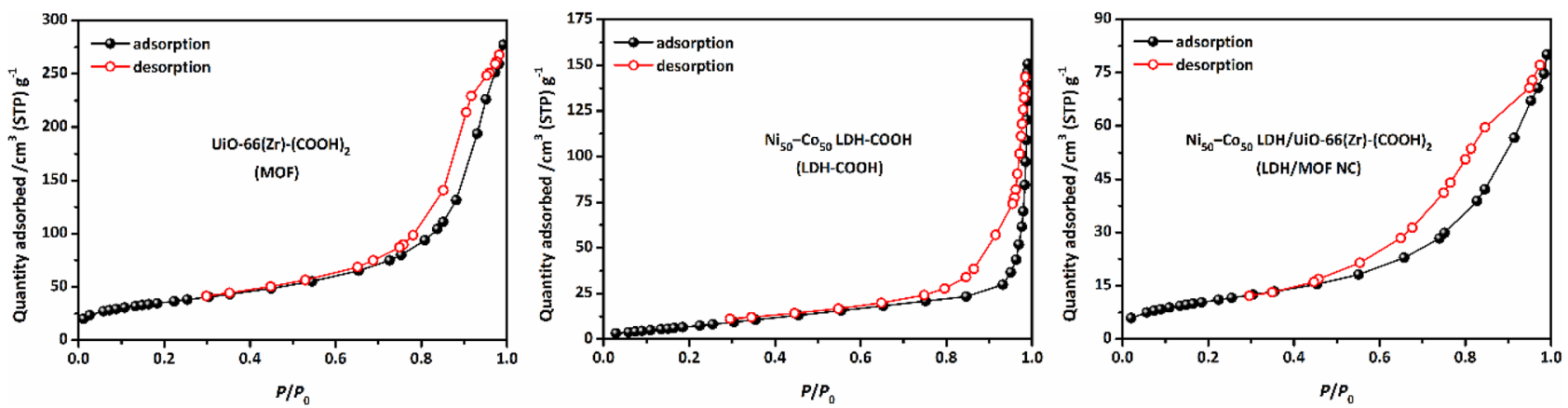

Figure 4. $\mathrm{N}_{2}$ adsorption-desorption isotherms of the samples. 


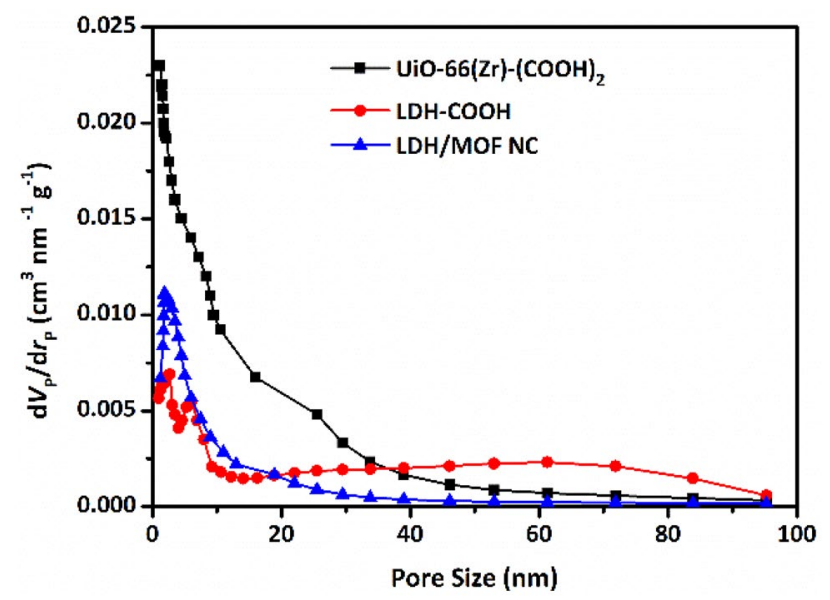

Figure 5. BJH pore size distribution of the samples.

exhibits a combination of Type $1(b)$ and Type IV(a), which is characteristic of microporous and mesoporous material, respectively. Type $1(\mathrm{~b})$ isotherm is the result of a microporous solid having pore size distribution in the micro-meso range, including wide micropores (pore size: 1-2 nm) and possibly narrow mesopores (pore size: $<2.5 \mathrm{~nm})^{26}$. The $\mathrm{Ni}_{50} \mathrm{Co}_{50}-\mathrm{LDH}$ shows a Type III isotherm with a Type H1 hysteresis loop which is representative of the presence of mesopores and macropore ${ }^{27}$. Adsorption-desorption isotherms of $\mathrm{N}_{2}$ for LDH/MOF NC has a similar pattern to $\mathrm{UiO}-66(\mathrm{Zr})-(\mathrm{COOH})_{2}$, except that the $\mathrm{LDH} / \mathrm{MOF} \mathrm{NC}$ has a wider hysteresis loop than $\mathrm{UiO}$ $66(\mathrm{Zr})-(\mathrm{COOH})_{2}$, which can be attributed to the presence of larger mesopores in the LDH/MOF NC structure. The presence of such a bi-/trimodal pore system in a porous solid material can facilitate the mass transfer, which in turn can significantly improve the transfer rate of species in the system and, consequently, increase adsorption capacity and reduce equilibrium adsorption time $\mathrm{f}^{7,8,17,20,28}$. BJH pore size distribution of the samples (Fig. 5) revealed that $\mathrm{LDH} / \mathrm{MOF} \mathrm{NC}$ has a wider pore size distribution than pure $\mathrm{UiO}-66(\mathrm{Zr})-(\mathrm{COOH})_{2}$, which is in accordance with the findings from the hysteresis loops.

Adsorption studies. Characterization of the LDH/MOF NC structure showed that this hybrid material can be used as an effective adsorbent for the removal of heavy metal species due to its abundant adsorption sites within its porous structure. For this purpose, the adsorption behavior and the removal performance of the synthesized adsorbent for the uptake of $\mathrm{Cd}(\mathrm{II})$ and $\mathrm{Pb}(\mathrm{II})$ cations were studied. A batch adsorption system for removal of $\mathrm{Cd}(\mathrm{II})$ and $\mathrm{Pb}(\mathrm{II})$ was used to investigate the adsorption behavior of $\mathrm{Cd}(\mathrm{II})$ and $\mathrm{Pb}(\mathrm{II})$ on the $\mathrm{LDH} /$ MOF NC as an adsorbent. For this purpose, the influence of important adsorption parameters affecting the adsorption performance of the adsorbent was studied at room temperature $\left(T=25^{\circ} \mathrm{C}\right)$, including the effect of $\mathrm{pH}$, adsorbent dose, initial metal concentration, and contact time. The heavy metal adsorption capacity on the adsorbent at equilibrium and any time $t$, as well as removal percentage, can be calculated using the following equations $^{29}$ :

$$
\begin{gathered}
Q_{\mathrm{e}}=\left(C_{\mathrm{i}}-C_{\mathrm{e}}\right) \times(V / W) \\
Q_{\mathrm{t}}=\left(C_{\mathrm{i}}-C_{\mathrm{t}}\right) \times(V / W) \\
\text { \%Removal }=100 \cdot\left[\left(C_{\mathrm{i}}-C_{\mathrm{e}}\right) / C_{\mathrm{e}}\right]
\end{gathered}
$$

where $Q_{\mathrm{e}}$ and $Q_{\mathrm{t}}$ represent the uptake capacity of heavy metals at equilibrium $\left(\mathrm{mg} \mathrm{g}^{-1}\right)$ and any time $t\left(\mathrm{mg} \mathrm{g}^{-1}\right)$, respectively. $C_{\mathrm{i}}, C_{\mathrm{e}}$, and $C_{\mathrm{t}}$ are heavy metal concentration $\left(\mathrm{mg} \mathrm{g}^{-1}\right)$ at the initial stage (before adsorption), at equilibrium, and at any time $t$, respectively. $V$ and $W$ parameters are the volume of heavy metal solution (L) and mass of the adsorbent $(\mathrm{g})$, respectively.

In the adsorption process, $\mathrm{pH}$ and adsorbent dose factors have a direct effect on the amount of adsorption. It has been reported that solution $\mathrm{pH}$ has the most significant effect on the physicochemical properties of the adsorbent surface as well as the solution chemistry ${ }^{30,31}$. Therefore, the simultaneous effects of $\mathrm{pH}$ and adsorbent dose on the removal of $\mathrm{Cd}(\mathrm{II})$ cations by the $\mathrm{LDH} / \mathrm{MOF}$ NC were monitored and the results are shown in Fig. 6.

For both heavy metals, as the $\mathrm{pH}$ increases from 2.0 to 5.0, the removal percentage increases steadily to reach its maximum level ( $\mathrm{pH}$ 5.0) and then decreases slightly until the $\mathrm{pH}$ value of 7.0 above which begins to decrease significantly. This adsorption trend can be seen in all three adsorbent doses. Soltani et al. ${ }^{12}$ have reported that this trend of increasing-maximum-decreasing (IMD) pattern is observed in many cases for the adsorption of cationic heavy metals on adsorbents with active functional groups such as $-\mathrm{OH},-\mathrm{SH},-\mathrm{NH},-\mathrm{NH}_{2}$, and $-\mathrm{C}=\mathrm{O}$.

In acidic $\mathrm{pHs}(\mathrm{pH}=2.0-4.0)$, metal adsorption is low due to the competition between proton $\left(\mathrm{H}_{3} \mathrm{O}^{+}\right)$and metal cations for interaction with functional groups (carboxylate groups) ${ }^{32}$. Moreover, according to the previous studies $^{33}$, in low $\mathrm{pH}$ environments, low adsorption is observed due to the repulsive interaction between cationic 

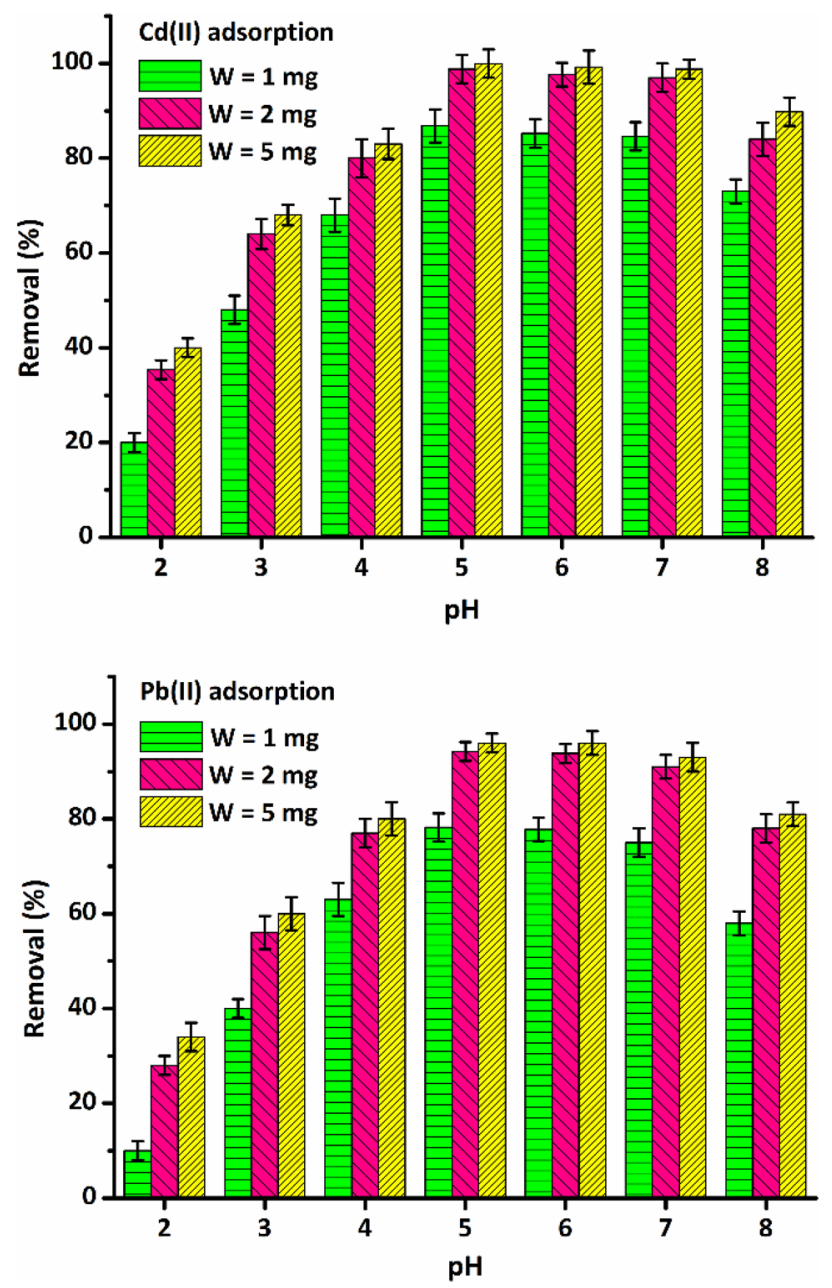

Figure 6. The effect of $\mathrm{pH}$ and adsorbent dose on the removal performance of the adsorbent toward Cd(II) and $\mathrm{Pb}(\mathrm{II})$ cations $\left(V=20 \mathrm{~mL}, C_{\mathrm{i}}=25 \mathrm{mg} \mathrm{L}^{-1}, t=120 \mathrm{~min}, T=25^{\circ} \mathrm{C}\right.$, shaking speed $200 \mathrm{rpm}$ ).

adsorbate species and the positive surface charge of the MOF. Gradually, with increasing $\mathrm{pH}$ of the solution and decreasing competition, the adsorption increases to reach its maximum at a certain point, then with further increase in the $\mathrm{pH}$ and augmenting the concentration of hydroxide anions, metal cations begin to interact with them, which reduces the adsorption on the adsorbent surface. Zhao et al. ${ }^{18}$ reported that with increasing $\mathrm{pH}$ of the solution, the carboxylic form of linkers $(-\mathrm{COOH})$ is converted to carboxylate $\left(-\mathrm{COO}^{-}\right)$, which leads to a stronger interaction between functional groups and heavy metals cations, resulting in increased adsorption. Also, for both $\mathrm{Cd}(\mathrm{II})$ and $\mathrm{Pb}(\mathrm{II})$, with an increase in the amount of adsorbent from 1.0 to $2.0 \mathrm{mg}$, the removal percentage increased considerably, but with an increase to $5.0 \mathrm{mg}$, there was no significant increase in adsorption as shown in Fig. 6. It is reported that because of the stronger electron-accepting affinity of heavy metals like $\mathrm{Cd}(\mathrm{II})$ and $\mathrm{Pb}(\mathrm{II})$ cations than that of $\mathrm{H}_{3} \mathrm{O}^{+}$cations, acidic adsorption sites like carboxylic groups can be effective for the capture of metal cations ${ }^{18}$. Here, in acidic $\mathrm{pH} 5.0$ interaction between heavy metals and surface $-\mathrm{COOH}$ groups of adsorbent is stronger. Accordingly, pH 5.0 and an adsorbent dose of $2.0 \mathrm{mg}$ were selected as optimum conditions for further adsorption studies.

The effects of heavy metal concentration and contact time on the adsorption process were studied and are depicted in Fig. 7a,c. As shown in Fig. 7a, the changes in the adsorption capacity with equilibrium heavy metal concentration, with increasing heavy metal concentration the adsorption capacity increases dramatically until it is almost fixed at a point (experimental maximum adsorption capacity, $Q_{\mathrm{m} \text {,exp. }}\left(\mathrm{mg} \mathrm{g}^{-1}\right)$ ) and the adsorption reaches equilibrium. Also, an almost similar adsorption pattern was observed for adsorption capacity changes with increasing contact time (Fig. 7c).

In order to investigate the adsorption behavior of $\mathrm{Cd}(\mathrm{II})$ and $\mathrm{Pb}(\mathrm{II})$ cations on the synthesized LDH/MOF NC and to study the possible adsorption mechanism/s in the process different isotherm and kinetic models were fitted to experimental data. The non-linear equations of these isotherms (Langmuir, Freundlich, and Redlich-Peterson (RP)) and kinetics (pseudo-first-order (PFO), pseudo-second-order (PSO), and Elovich) are given as follows ${ }^{34}$ :

$$
\text { Langmuir : } Q_{\mathrm{e}}=Q_{\mathrm{m}, \text { cal. }} \cdot\left[\left(K_{\mathrm{L}} \cdot C_{\mathrm{e}}\right) /\left(1+K_{\mathrm{L}} \cdot C_{e}\right)\right.
$$



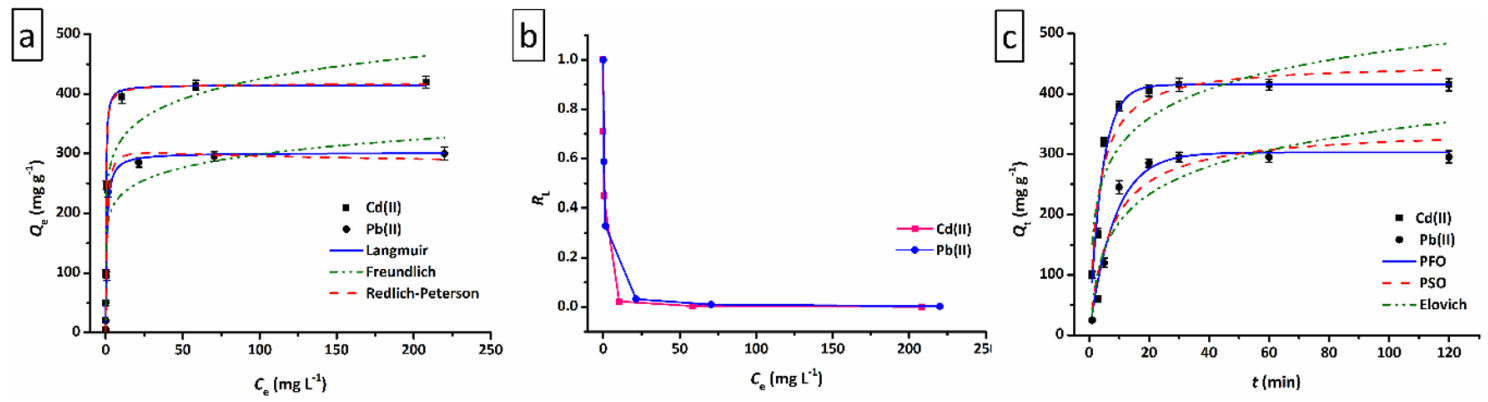

Figure 7. (a) The effect of equilibrium metal concentration on the adsorption capacity of $\mathrm{Cd}(\mathrm{II})$ and $\mathrm{Pb}$ (II) onto the LDH/MOF NC adsorbent and non-linear fitting of experimental data to different isotherm models, and (b) corresponding $R_{\mathrm{L}}$ values ( $\mathrm{pH}=5.0, W=0.02 \mathrm{~g}, V=20 \mathrm{~mL}, t=120 \mathrm{~min}, T=25^{\circ} \mathrm{C}$, shacking speed $=200 \mathrm{rpm}$ ); (c) The effect of contact time on the adsorption capacity of $\mathrm{Cd}$ (II) and $\mathrm{Pb}$ (II) onto LDH/MOF NC adsorbent and non-linear fitting of experimental data to different kinetic models $(\mathrm{pH}=5.0, W=0.02 \mathrm{~g}, V=20 \mathrm{~mL}$, $C_{\mathrm{i}}=100 \mathrm{mg} \mathrm{L}^{-1}, T=25^{\circ} \mathrm{C}$, shacking speed $=200 \mathrm{rpm}$ ).

\begin{tabular}{|c|c|c|c|c|c|c|c|}
\hline \multicolumn{4}{|l|}{ Isotherms } & \multicolumn{4}{|l|}{ Kinetics } \\
\hline \multirow[b]{2}{*}{ Models } & \multirow[b]{2}{*}{ Parameters (unit) } & \multicolumn{2}{|l|}{ Values } & \multirow[b]{2}{*}{ Models } & \multirow[b]{2}{*}{ Parameters (unit) } & \multicolumn{2}{|l|}{ Values } \\
\hline & & Cd(II) & $\mathrm{Pb}(\mathrm{II})$ & & & Cd(II) & $\mathrm{Pb}(\mathrm{II})$ \\
\hline \multirow{4}{*}{ Langmuir } & $Q_{m, \exp }\left(\mathrm{mg} \mathrm{g}^{-1}\right)$ & 420.5 & 300.3 & & $Q_{e, \exp .}\left(\mathrm{mg} \mathrm{g}^{-1}\right)$ & 415.0 & 295.4 \\
\hline & $Q_{\mathrm{m}, \text { cal. }}\left(\mathrm{mg} \mathrm{g}^{-1}\right)$ & 415.3 & 301.4 & \multirow{3}{*}{ PFO } & $Q_{\mathrm{e}, \mathrm{cal}}\left(\mathrm{mg} \mathrm{g}^{-1}\right)$ & 415.3 & 302.6 \\
\hline & $K_{\mathrm{L}}\left(\mathrm{L} \mathrm{mg}^{-1}\right)$ & 4.073 & 1.405 & & $k_{1}\left(\min ^{-1}\right)$ & 0.2368 & 0.1199 \\
\hline & $R^{2}$ & 0.9810 & 0.9515 & & $R^{2}$ & 0.9686 & 0.9663 \\
\hline \multirow{3}{*}{ Freundlich } & $K_{\mathrm{F}}\left(\left(\mathrm{mg} \mathrm{g}^{-1}\right)\left(\mathrm{L} \mathrm{mg}^{-1}\right)^{1 / \mathrm{n}}\right)$ & 245.27 & 177.54 & \multirow{4}{*}{ PSO } & $Q_{\mathrm{e}, \mathrm{cal} .}\left(\mathrm{mg} \mathrm{g}^{-1}\right)$ & 450.4 & 342.7 \\
\hline & $n(-)$ & 8.37 & 8.85 & & $k_{2} \times 10^{-4}\left(\mathrm{~g} \mathrm{mg}^{-1} \mathrm{~min}^{-1}\right)$ & 7.36 & 4.17 \\
\hline & $R^{2}$ & 0.9074 & 0.8809 & & $h\left(\mathrm{~g} \mathrm{mg}^{-1} \mathrm{~min}^{-1}\right)$ & 149.3 & 49.0 \\
\hline \multirow{4}{*}{$\mathrm{R}-\mathrm{P}$} & $K_{\mathrm{R}-\mathrm{P}}\left(\mathrm{L} \mathrm{g}^{-1}\right)$ & 1716.2 & 371.2 & & $R^{2}$ & 0.9266 & 0.9147 \\
\hline & $\alpha_{\mathrm{R}-\mathrm{P}}\left(\mathrm{mg} \mathrm{L}^{-1}\right)^{-\mathrm{g}}$ & 4.182 & 1.087 & \multirow{3}{*}{ Elovich } & $\alpha\left(\mathrm{mg} \mathrm{g}^{-1} \min ^{-1}\right)$ & 610.76 & 109.94 \\
\hline & $g(-)$ & 0.9969 & 0.9989 & & $\beta\left(\mathrm{g} \mathrm{mg}^{-1}\right)$ & 0.0144 & 0.145 \\
\hline & $R^{2}$ & 0.9773 & 0.9445 & & $R^{2}$ & 0.7640 & 0.8317 \\
\hline
\end{tabular}

Table 3. The obtained values for isotherm and kinetic parameters using the non-linear fitting method.

$$
\begin{gathered}
\text { Freundlich }: K_{\mathrm{F}} \cdot C_{\mathrm{e}}^{1 / n} \\
\mathrm{R}-\mathrm{P}:\left[\left(K_{\mathrm{R}-\mathrm{P}} \cdot C_{\mathrm{e}}\right) /\left(1+\alpha_{\mathrm{R}-\mathrm{P}} \cdot C_{\mathrm{e}}^{g}\right)\right] \\
\text { PFO : } Q_{\mathrm{t}}=Q_{\mathrm{e}, \mathrm{cal} .} \cdot\left[1-\exp \left(-k_{1} \cdot t\right)\right] \\
\text { PSO: } Q_{\mathrm{t}}=\left[k_{2} \cdot Q_{\mathrm{e}, \mathrm{cal}}^{2} \cdot t\right] /\left[1+Q_{\mathrm{e}, \mathrm{cal}} \cdot k_{2} \cdot t\right] \\
\text { Elovich: } Q_{\mathrm{t}}=\left[\left(\frac{1}{\beta}\right) \cdot(\ln \alpha \cdot \beta) \cdot t\right]
\end{gathered}
$$

where, in the Langmuir equation, $Q_{\mathrm{m} \text {,cal. }}$ and $K_{\mathrm{L}}$ represent the calculated maximum adsorption capacity of the adsorbent at equilibrium $\left(\mathrm{mg} \mathrm{g}^{-1}\right)$ and Langmuir isotherm constant $\left(\mathrm{L} \mathrm{g}^{-1}\right)$, respectively. $K_{\mathrm{L}}$ and $n$ are, Freundlich isotherm constant $\left(\mathrm{mg} \mathrm{g}^{-1}\right)\left(\mathrm{mg} \mathrm{L}^{-1}\right)^{-1 / n}$ and a parameter representative of the adsorption intensity (dimensionless) in the Freundlich isotherm, respectively. $K_{\mathrm{R}-\mathrm{P}}\left(\mathrm{L} \mathrm{g}^{-1}\right), \alpha_{\mathrm{R}-\mathrm{P}}\left(\mathrm{mg} \mathrm{L}^{-1}\right)^{-g}$, and $g$ (dimensionless) are R-P isotherm constants, where $0 \leq g \leq 1$. In the aforementioned kinetic equations, $Q_{\mathrm{e}, \text { cal., }}, k_{1}, k_{2}, \alpha$, and $\beta$ are the calculated uptake capacity at equilibrium time $\left(\mathrm{mg} \mathrm{g}^{-1}\right)$, the rate constant in the PFO model $\left(\mathrm{min}^{-1}\right)$, the rate constant in the PSO model $\left(\mathrm{g} \mathrm{mg}^{-1} \mathrm{~min}^{-1}\right)$, the initial adsorption rate $\left(\mathrm{mg} \mathrm{g}^{-1} \mathrm{~min}^{-1}\right)$ in the Elovich model, and the adsorption constant $\left(\mathrm{g} \mathrm{mg}^{-1}\right)$ in the Elovich model, respectively.

The values of isotherm and kinetic parameters as well as the $R^{2}$ values obtained from the non-linear fitting method are given in Table 3. Compared to the Freundlich model, the Langmuir model has a higher $R^{2}$ value for adsorption of both $\mathrm{Cd}(\mathrm{II})$ and $\mathrm{Pb}$ (II) on the adsorbent. Also, the amounts of $Q_{\mathrm{m} \text {,cal. }}$ (for $\mathrm{Cd}(\mathrm{II})=415.3 \mathrm{mg} \mathrm{g}^{-1}$ and for $\mathrm{Pb}(\mathrm{II})=301.4 \mathrm{mg} \mathrm{g}^{-1}$ ) in the Langmuir model was close to the experimental maximum adsorption capacities $\left(Q_{\mathrm{m} \text {,exp. }}=420.5\right.$ and 300.3 for $\mathrm{Cd}(\mathrm{II})$ and $\mathrm{Pb}(\mathrm{II})$, respectively), so the Langmuir model is in better agreement with 


\section{$\mathrm{Ni}_{50} \mathrm{CO}_{50}$-LDH-COOH/UiO-66(Zr)-(COOH $)_{2} \mathrm{NC}$ [LDH/MOF NC]}

Adsorption of $\mathrm{Cd}$ (II) and $\mathrm{Pb}$ (II)

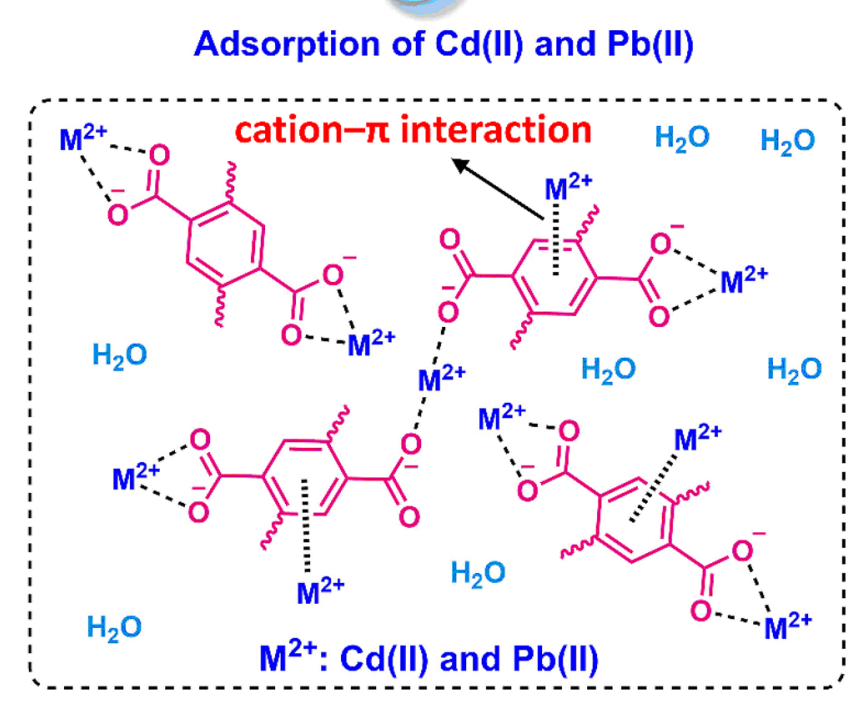

\section{Heavy metals adsorption from aqueous solution}

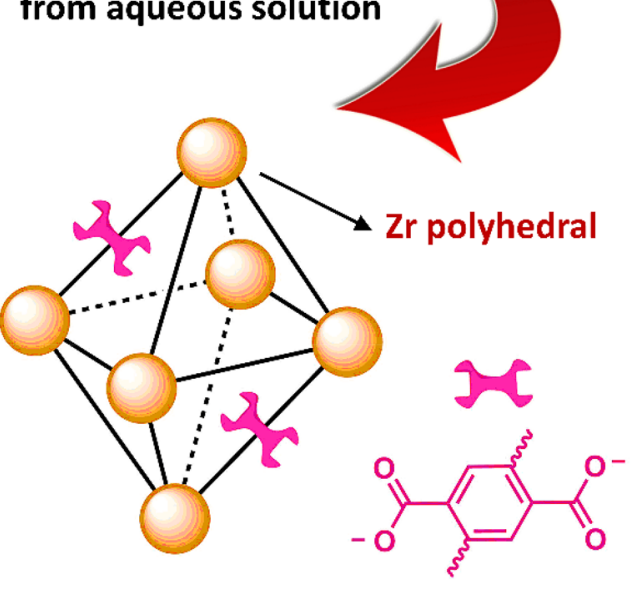

UiO-66(Zr)-(COOH) 2 MOF Linker

Possible interaction mechanisms

\section{$\square$ Direct bonding between metal cations with the free hydroxyl groups on the surface of $\mathrm{Ni}_{50} \mathrm{CO}_{50}-\mathrm{LDH}-\mathrm{COOH}$ $\square$ Surface complexation (complexation of $\mathrm{Cd}(\mathrm{II})$ and $\mathrm{Pb}$ (II) with $-\mathrm{COO}^{-}$groups) $\square$ Cation $-\pi$ interaction}

Scheme 2. Possible interactions between heavy metals, $\mathrm{Cd}(\mathrm{II})$ and $\mathrm{Pb}(\mathrm{II})$, and the surface of the $\mathrm{Ni}_{50} \mathrm{Co}_{50}-\mathrm{LDH}$ $\mathrm{COOH} / \mathrm{UiO}-66(\mathrm{Zr})-(\mathrm{COOH})_{2} \mathrm{NC}$ adsorbent.

the experimental data and can provide an appropriate isotherm approximation. Based on the Langmuir isotherm, the maximum uptake capacity is related to the complete monolayer coverage on the adsorbent surface ${ }^{35}$. The R-P isotherm can be applied to determine whether the adsorption behavior follows the Freundlich or the Langmuir. In the R-P model, when $g=0$ and $g=1 \mathrm{R}-\mathrm{P}$ equation becomes the Freundlich equation and the Langmuir equation, respectively ${ }^{5,8,20}$. For adsorption of both $\mathrm{Cd}(\mathrm{II})$ and $\mathrm{Pb}(\mathrm{II})$, the value of this parameter was very close to unity, demonstrating that the equilibrium data for adsorption of these heavy metals on the LDH/MOF NC fit much better with the Langmuir model than the Freundlich model. The Langmuir model assumes that the adsorption phenomenon takes place on the surface of the LDH/MOF HNC adsorbent with a limited number of identical localized sites via a monolayer coverage.

According to Hall et al. ${ }^{36}$ an essential feature of the Langmuir model could be demonstrated in terms of separation factor $\left(R_{\mathrm{L}}\right)$ which is a dimensionless equilibrium parameter and suggests the adsorption nature and possibility of the adsorption process: $R_{\mathrm{L}}=0$, irreversible; $0<R_{\mathrm{L}}<1$, favorable; $R_{\mathrm{L}}=1$, linear; $R_{\mathrm{L}}>1$, unfavorable. As shown in Fig. 7b, for the adsorption of $\mathrm{Cd}(\mathrm{II})$ and $\mathrm{Pb}(\mathrm{II})$ cations on the synthesized LDH/MOF NC adsorbent, the values obtained are between zero and one, implying a favorable adsorption process.

By evaluating the theoretical values of the kinetic parameters obtained after the non-linear fit of the experimental equilibrium data for the adsorption of both $\mathrm{Cd}(\mathrm{II})$ and $\mathrm{Pb}(\mathrm{II})$, it was found that the $\mathrm{PFO}$ and $\mathrm{PSO}$ kinetic models have higher values of $R^{2}$ than the Elovich models. Also, compared to the PSO model, the PFO model has

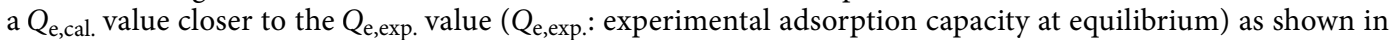
Table 3. Consequently, it can be concluded that the adsorption mechanism of $\mathrm{Cd}$ (II) and $\mathrm{Pb}$ (II) cations on the $\mathrm{LDF} / \mathrm{MOF} \mathrm{NC}$ in an aqueous media is a combination of the PFO and PSO kinetic models with more characteristics of the PFO model, suggesting that the adsorption process takes place initially via the fast response (PFO model). The PFO model points that the rate of adsorption site occupation on the adsorbent is proportional to the number of unoccupied adsorption sites. The PSO kinetic model assumes the rate-limiting step as the formation of a chemisorptive type bond involving sharing or exchange of electrons between surface functional groups of adsorbent and adsorbate.

As a result and based on the data obtained from isotherm and kinetic models, it can be suggested that the adsorption mechanism of $\mathrm{Cd}(\mathrm{II})$ and $\mathrm{Pb}$ (II) on the synthesized LDF/MOF NC is monolayer adsorption on a homogeneous surface with an initial fast adsorption response involving a combination of cation $-\pi$ interactions (between heavy metal cations and $\pi$ electron cloud of the aromatic system in MOF structure) and chemisorption involving valency forces through sharing or exchange of electrons (between carboxylate functional groups as complexing functionality and heavy metal cations as well as direct bonding between metal cations with the free hydroxyl and amine groups on the surface of $\mathrm{Ni}_{50} \mathrm{Co}_{50}-\mathrm{LDH}-\mathrm{COOH}$ ), as depicted in Scheme 2 . 


\begin{tabular}{|c|c|c|c|c|c|c|c|c|}
\hline \multirow[b]{2}{*}{ Adsorbents } & \multirow[b]{2}{*}{ Res. groups } & \multirow[b]{2}{*}{ Year } & \multicolumn{2}{|c|}{$Q_{\mathrm{m}, \mathrm{cal} .}\left(\mathrm{mg} \mathrm{g}^{-1}\right)$} & \multicolumn{3}{|c|}{ Conditions } & \multirow[b]{2}{*}{ Ref. } \\
\hline & & & Cd(II) & $\mathrm{Pb}(\mathrm{II})$ & $\mathrm{pH}$ & $\begin{array}{l}t(\min \text { or } \\
\left.\mathbf{h}^{-1}\right)\end{array}$ & $T\left({ }^{\circ} \mathrm{C}\right)$ & \\
\hline LDH/MOF NC & Soltani et al. & 2020 & 415.3 & 301.4 & 5.0 & $120 \mathrm{~min}$ & 25 & This work \\
\hline COOH-KCC-1/PA6 NC & Soltani et al. & 2020 & 109.2 & - & 7.0 & $240 \mathrm{~min}$ & 25 & 29 \\
\hline CSt-ZnO & Naushad et al. & 2020 & - & 256.4 & 6.0 & $120 \mathrm{~min}$ & 25 & 37 \\
\hline TATS@AC & Naushad et al. & 2020 & 177.3 & - & 7.5 & $240 \mathrm{~min}$ & 25 & 38 \\
\hline Cu-BTC MOF & Hasankola et al. & 2019 & - & 333 & 5.0 & $25 \mathrm{~min}$ & RT & 39 \\
\hline Zn-BTC MOF & & & - & 312 & 5.0 & $25 \mathrm{~min}$ & RT & 39 \\
\hline UiO-66-EDTA & Wu et al. & 2019 & 237.2 & 357.9 & 5.0 & $30 \mathrm{~min}$ & 30 & 32 \\
\hline TA-KCC-1/Chi-OLA NCs & Zarei et al. & 2019 & - & 168 & 9.0 & $100 \mathrm{~min}$ & 25 & 4 \\
\hline TAS-HMSs & Soltani et al. & 2019 & 251.7 & 295.4 & 5.0 & $120 \mathrm{~min}$ & 25 & 12 \\
\hline M-MCM-41/PVOH NC & Soltani et al. & 2018 & 46.7 & - & 6.0 & $240 \mathrm{~min}$ & RT & 40 \\
\hline $\mathrm{ZnO}$ nanoflowers & Kataria et al. & 2018 & 71.5 & 115 & 6.0 & $120 \mathrm{~min}$ & NR & 41 \\
\hline CS-LDH & Lyu et al. & 2018 & 140.8 & 333.3 & $\sim 6.0$ & $60 \mathrm{~min}$ & 25 & 42 \\
\hline Melamine-MOFs & Yin et al. & 2018 & - & 122.0 & 5.0 & $120 \mathrm{~min}$ & 40 & 43 \\
\hline MOFs & & & - & 72.1 & 5.0 & $120 \mathrm{~min}$ & 40 & 43 \\
\hline $\mathrm{UiO}-66-\mathrm{NH}_{2}$ & Wang et al. & 2017 & 177.3 & 92.2 & 6.0 & $120 \mathrm{~min}$ & 30 & 44 \\
\hline $\mathrm{Cu}_{3}(\mathrm{BTC})_{2}-\mathrm{SO}_{3} \mathrm{H}$ & Wang et al. & 2015 & 88.7 & - & 6.0 & $10 \mathrm{~min}$ & RT & 45 \\
\hline CFR & Naushad et al. & 2015 & 322.6 & - & 7.0 & $60 \mathrm{~min}$ & 25 & 46 \\
\hline DSDH & Shahat et al. & 2015 & - & 169.3 & 5.2 & $3 \mathrm{~h}$ & RT & 47 \\
\hline LDH-H & González et al. & 2014 & $\sim 39$ & $\sim 100$ & $7.0-8.0$ & $48 \mathrm{~h}$ & RT & 48 \\
\hline $\mathrm{NH}_{2}-\mathrm{MCM}-41$ & Heidari et al. & 2009 & 18.3 & 57.7 & $2.5-5.0$ & $120 \mathrm{~min}$ & 25 & 49 \\
\hline
\end{tabular}

Table 4. Adsorption capacities for $\mathrm{Cd}(\mathrm{II})$ and $\mathrm{Pb}(\mathrm{II})$ by various $\mathrm{LDH}$-based and MOF-based adsorbents as well as the other nanoporous adsorbents ( $R T$ room temperature, $N R$ not reported). COOH-KCC-1/PA6 NC carboxylic acid-functionalized fibrous silica KCC-1/polyamide 6 nanocomposite; CSt- $\mathrm{ZnO}$ starch based $\mathrm{ZnO}$ nanocomposite; TATS@AC triaminotriethoxysilane grafted oxidized activated carbon; TA-KCC-1/Chi-OLA NCs triamine-functionalised mesoporous fibrous silica KCC-1/chitosan-oleic acid nanocomposite; TAS$H M S$ s triamine-functionalized $\mathrm{SiO}_{2}$ hollow microspheres; $M-M C M-41 / P V O H$ NC amino-modified MCM-41/ poly(vinyl alcohol) nanocomposite; $C S-L D H$ chitosan/Mg-Al-layered double hydroxide nanocomposite; CFR curcumin (7-bis(4-hydroxy-3-methoxyphenyl)-1,6-heptadiene-3,5-dione) formaldehyde resin; $D S D H$ $\mathrm{N}, \mathrm{N}^{\prime}$ di(3-carboxysalicylidene)-3,4diamino-5-hydroxypyrazole.

Other plausible mechanisms involve diffusion into micropores and mesopores of the LDF/MOF NC, bulk transport in the liquid phase, mass-transport processes, and diffusion across the liquid film surrounding the LDF/MOF NC.

The most important characteristics of an adsorbent material that directly affect the rate of adsorption and equilibrium adsorption capacity are (1) the degree of porosity and specific surface area, (2) surface functionality and the physicochemical nature of the adsorbent surface, (3) the availability of that surface and its active adsorption sites to adsorbate species, and (4) the morphology and physical size of the adsorbent particles. The $\mathrm{Ni}_{50} \mathrm{Co}_{50}-\mathrm{LDH}-\mathrm{COOH} / \mathrm{UiO}-66(\mathrm{Zr})-(\mathrm{COOH})_{2} \mathrm{NC}$ synthesized in this study, having all these properties, can play the role of an effective adsorbent for the removal of toxic heavy metal cations from aqueous solution.

Comparison study. The synthesized LDH/MOF NC possesses a considerably enhanced adsorption capacity for both $\mathrm{Cd}(\mathrm{II})$ and $\mathrm{Pb}(\mathrm{II})$ cations compared with most LDH-based and MOF-based adsorbents as well as the other nanoporous adsorbents (Table 4). Furthermore, in comparison to other MOF-based and LDH-based adsorbents, as well as the other nanoporous adsorbents, that have been synthesized using toxic organic solvents, the LDH/MOF NC adsorbent was prepared using environmentally friendly solvents such as water and ethylene glycol.

\section{Conclusions}

Here, for the first time, we have developed a new LDH/MOF NC using a simple, effective, and green in situ approach in a round bottom flask under ambient pressure conditions. MOF nanocrystals (UiO-66-(Zr)$\left.(\mathrm{COOH})_{2}\right)$ were grafted and grown uniformly over the whole surface of micrometer-sized ultrathin nanosheets of $\mathrm{COOH}$-functionalized $\mathrm{LDH}\left(\mathrm{Ni}_{50} \mathrm{Co}_{50}-\mathrm{LDH}-\mathrm{COOH}\right)$ in a typical solvothermal condition at $100{ }^{\circ} \mathrm{C}$ in a water system. XRD, FT-IR, FESEM-EDX mapping, TEM, and $\mathrm{N}_{2}$ adsorption-desorption analyses were applied to characterize and investigate the physicochemical properties of the synthesized samples. The prepared LDH/MOF NC was used as a potential adsorbent for the uptake of $\mathrm{Cd}(\mathrm{II})$ and $\mathrm{Pb}(\mathrm{II})$ heavy metals cations from aqueous solution and the influence of $\mathrm{pH}$, adsorbent dose, initial metal concentration, and contact time on the adsorption process were investigated. Several non-linear isotherm and kinetic models were applied to find plausible mechanisms involved in the $\mathrm{Cd}(\mathrm{II})$ and $\mathrm{Pb}$ (II) adsorption, and it was found that the Langmuir and pseudo-first-order models have the best agreement with isotherm and kinetic data, respectively. The calculated maximum adsorption 


\begin{tabular}{|l|l|l|}
\hline Chemical & Purity/grade & Company \\
\hline $1,2,4,5$-Benzenetetracarboxylic acid $($ Pyromellitic acid) & $96 \%$ & Sigma-Aldrich \\
\hline Zirconium(IV) chloride $\left(\mathrm{ZrCl}_{4}\right)$ & $\geq 99.9 \%$ & Sigma-Aldrich \\
\hline Nickel(II) nitrate hexahydrate $\left[\mathrm{Ni}\left(\mathrm{NO}_{3}\right)_{2} \cdot 6 \mathrm{H}_{2} \mathrm{O}\right]$ & $\geq 98.5 \%$ & Sigma-Aldrich \\
\hline Cobalt(II) nitrate hexahydrate $\left[\mathrm{Co}\left(\mathrm{NO}_{3}\right)_{2} \cdot 6 \mathrm{H}_{2} \mathrm{O}\right]$ & $98 \%$ & Sigma-Aldrich \\
\hline Cadmium nitrate tetrahydrate $\left[\mathrm{Cd}\left(\mathrm{NO}_{3}\right)_{2} \cdot 4 \mathrm{H}_{2} \mathrm{O}\right]$ & $\geq 99.9 \%$ & Sigma-Aldrich \\
\hline (3-Aminopropyl)triethoxysilane & $99 \%$ & Sigma-Aldrich \\
\hline Ethylene glycol (EG) & $\geq 98.0 \%$ & Merck \\
\hline Ethanol & Absolute and $96 \%$ & Merck \\
\hline Acetone & $99 \%$ & Merck \\
\hline Sodium hydroxide pellets $(\mathrm{NaOH})$ & $99 \%$ & Merck \\
\hline Hydrochloric acid $(\mathrm{HCl})$ & $36 \%$ & Merck \\
\hline
\end{tabular}

Table 5. Chemicals.

capacities of $\mathrm{Cd}(\mathrm{II})$ and $\mathrm{Pb}(\mathrm{II})$ by the $\mathrm{LDH} / \mathrm{MOF} \mathrm{NC}$ were found to be 415.3 and $301.4 \mathrm{mg} \mathrm{g}^{-1}$ based on the Langmuir isotherm model ( $\mathrm{pH}=5.0, W=0.02 \mathrm{~g}, V=20 \mathrm{~mL}, t=120 \mathrm{~min}, T=25^{\circ} \mathrm{C}$, shaking speed $200 \mathrm{rpm}$ ). The results of this study revealed that the LDH/MOF NCs could potentially be used as a promising highly efficient green adsorbent for the removal of toxic metal cations from water.

\section{Methods}

Materials. All chemicals were used without further purification and are listed in Table 5.

Synthesis of $\mathrm{Ni}_{50} \mathrm{Co}_{50}-\mathrm{LDH}$. Following the procedure reported by Soltani et al. ${ }^{20,21}$, in a 1000 -mL three-

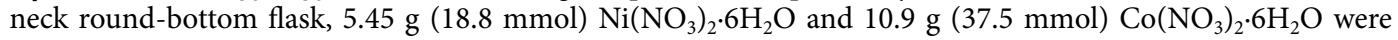
completely dissolved in a mixture of water/EG $(112.5 \mathrm{~mL} / 280 \mathrm{~mL})$ under refluxing and vigorous magnetic stirring $\left(90{ }^{\circ} \mathrm{C}\right)$. After fixing the temperature of the mixture at the desired point, $16.9 \mathrm{~g}(281.3 \mathrm{mmol})$ urea was slowly added and the resulting mixture was magnetically stirred under reflux for $3 \mathrm{~h}\left(90{ }^{\circ} \mathrm{C}\right)$. At the end of the reaction time, the mixture was cooled, Buchner-filtered, and repeatedly washed with water and ethanol. Finally, the resulting pale green precipitate was dried at $60^{\circ} \mathrm{C}$ for $24 \mathrm{~h}$.

Synthesis of $\mathrm{Ni}_{50} \mathrm{Co}_{50}-\mathrm{LDH}-\mathrm{COOH}$ (LDH-COOH). Carboxylic acid-functionalized LDH (LDH$\mathrm{COOH}$ ) was synthesized according to the following method: $1.0 \mathrm{~g} \mathrm{LDH}$ and a certain amount of APTES was introduced into a round bottom flask containing $60 \mathrm{~mL}$ ethanol and ultrasonicated for $15 \mathrm{~min}$. Afterward, the mixture was refluxed $(24 \mathrm{~h})$, cooled to room temperature, filtered off, washed with ethanol and water, and ovendried for $24 \mathrm{~h}$. The resulting fine powder was then added to a round bottom flask containing $0.4 \mathrm{~g}$ pyromellitic acid and $60 \mathrm{~mL}$ ethanol and ultrasonicated for $15 \mathrm{~min}$. The mixture was then refluxed at $160^{\circ} \mathrm{C}$ for $12 \mathrm{~h}$. Finally, the reaction mixture was cooled, Buchner-filtered, repeatedly washed with water and ethanol, and the resulting precipitate was dried (at $40^{\circ} \mathrm{C}$ for $12 \mathrm{~h}$ and $100^{\circ} \mathrm{C}$ for $12 \mathrm{~h}$ ).

Synthesis of UiO-66(Zr)-(COOH $)_{2}$. Pure UiO-66 $(\mathrm{Zr})-(\mathrm{COOH})_{2}$ crystals were prepared according to the method developed by Yang et al. ${ }^{23}$.

Synthesis of $\mathrm{Ni}_{50} \mathrm{Co}_{50}$-LDH-COOH/UiO-66(Zr)-(COOH) 2 nanocomposite (LDH/MOF NC). $1.0 \mathrm{~g}$ $\mathrm{LDH}-\mathrm{COOH}$ was added into $250 \mathrm{~mL}$ round bottom flask containing $100 \mathrm{~mL}$ water and ultrasonicated for $15 \mathrm{~min}$. Then, $0.8 \mathrm{~g} \mathrm{ZrCl}_{4}$ and $1.5 \mathrm{~g}$ pyromellitic acid was added to it under stirring and the resulting mixture was refluxed under stirring at $100{ }^{\circ} \mathrm{C}$ for $16 \mathrm{~h}$. Finally, the reaction mixture was allowed to cool to room temperature, Buchner-filtered, repeatedly washed with acetone, and the resulting white precipitate was dried at $30^{\circ} \mathrm{C}$ for $24 \mathrm{~h}$.

Batch experiments. An appropriate quantity of analytical grade $\mathrm{Cd}(\mathrm{II})$ and $\mathrm{Pb}(\mathrm{II})$ metal salt was used to prepare $1000 \mathrm{mg} \mathrm{L}^{-1}$ standard stock solution in pure water, and working standards of various concentrations of $\mathrm{Cd}(\mathrm{II})$ and $\mathrm{Pb}(\mathrm{II})$ were prepared daily by diluting the standard stock solution in pure water.

Effect of solution $\mathrm{pH}$ and adsorbent dose. Various adsorbent doses of $\mathrm{LDH} / \mathrm{MOF} \mathrm{NC}(W=0.01,0.02$, or $0.05 \mathrm{~g}$ ) were introduced into the stoppered $100-\mathrm{mL}$ polypropylene (PP) bottles containing $20.0 \mathrm{~mL}$ aqueous solution with $25 \mathrm{mg} \mathrm{L}^{-1}$ of $\mathrm{Cd}(\mathrm{II})$ and $\mathrm{Pb}(\mathrm{II})$ cations. The $\mathrm{pH}$ of the solution ranged from 2.0 to 8.0 and a $0.1 \mathrm{~mol} \mathrm{~L}^{-1} \mathrm{NaOH}$ or $1.0 \mathrm{~mol} \mathrm{~L}^{-1} \mathrm{HCl}$ was utilized to adjust the $\mathrm{pH}$ of the solution throughout the adsorption tests when desired. The PP bottles were then transformed into an incubator shaker with a thermostat and vibrated at $200 \mathrm{rpm}$ and $25^{\circ} \mathrm{C}$ for $120 \mathrm{~min}$. Finally, the samples were centrifuged at $4500 \mathrm{rpm}$ for $5 \mathrm{~min}$ to isolate the $\mathrm{LDH} / \mathrm{MOF} \mathrm{NC}$ particles and the supernatant solution analyzed using FAAS to determine the residual Cd(II) and $\mathrm{Pb}(\mathrm{II})$ concentrations. 


\begin{tabular}{|l|l|l|}
\hline Characterization method/instrument & Model/company & Country \\
\hline Fourier transform infrared (FT-IR) & Avatar 370, Thermo Nicole & USA \\
\hline $\begin{array}{l}\text { Field emission scanning electron microscopy-energy dispersive X-ray } \\
\text { (FESEM-EDX) }\end{array}$ & SIGMA HV, Zeiss & Germany \\
\hline $\mathrm{N}_{2}$ adsorption-desorption isotherm measurements (porosimetry analyzer) & Belsorp-mini II, BEL & Japan \\
\hline Powder X-ray diffraction (PXRD) & AW-XDM300, Asenware & China \\
\hline Flame atomic absorption spectroscopy (FAAS) & PerkinElmer Model A300 & Norwalk, USA \\
\hline
\end{tabular}

Table 6. Instruments and methods.

Adsorption isotherms and kinetics. For the isotherm tests, the initial volume of the $\mathrm{Cd}(\mathrm{II})$ and $\mathrm{Pb}$ (II) solutions was $20 \mathrm{~mL}$ containing different concentrations of $\mathrm{Cd}(\mathrm{II})$ and $\mathrm{Pb}$ (II) cations $\left(0.5-250 \mathrm{mg} \mathrm{L}^{-1}\right)$ and $0.002 \mathrm{~g}$ of LDH/MOF NC particles. The PP bottles were then transformed into an incubator shaker with a thermostat and vibrated at $200 \mathrm{rpm}$ and $25^{\circ} \mathrm{C}$ for $120 \mathrm{~min}$. Finally, the samples were centrifuged at $4500 \mathrm{rpm}$ for 5 min to isolate the LDH/MOF NC particles and the supernatant solution analyzed using FASS to determine the residual $\mathrm{Cd}(\mathrm{II})$ and $\mathrm{Pb}$ (II) concentrations. For kinetics testing, the conditions are similar to the above trend except that the initial concentration of heavy metals is $100 \mathrm{mg} \mathrm{L}^{-1}$, and the contact time varied between 1 and $120 \mathrm{~min}$.

Characterization. The instruments used to characterize the structures of the samples as well as to determine adsorbate concentrations are listed in Table 6.

Received: 13 November 2020; Accepted: 4 January 2021

Published online: 15 January 2021

\section{References}

1. Naushad, M., Mittal, A., Rathore, M. \& Gupta, V. Ion-exchange kinetic studies for $\mathrm{Cd}(\mathrm{II}), \mathrm{Co}(\mathrm{II}), \mathrm{Cu}(\mathrm{II})$, and $\mathrm{Pb}(\mathrm{II})$ metal ions over a composite cation exchanger. Desalin. Water Treat. 54, 2883-2890 (2015).

2. Naushad, M. Surfactant assisted nano-composite cation exchanger: Development, characterization and applications for the removal of toxic $\mathrm{Pb}^{2+}$ from aqueous medium. Chem. Eng. J. 235, 100-108 (2014).

3. Ihsanullah, et al. Heavy metal removal from aqueous solution by advanced carbon nanotubes: Critical review of adsorption applications. Sep. Purif. Technol. 157, 141-161 (2016)

4. Zarei, F., Marjani, A. \& Soltani, R. Novel and green nanocomposite-based adsorbents from functionalised mesoporous KCC-1 and chitosan-oleic acid for adsorption of $\mathrm{Pb}(\mathrm{II})$. Eur. Polym. J. 119, 400-409 (2019).

5. Soltani, R., Marjani, A. \& Shirazian, S. Facile one-pot synthesis of thiol-functionalized mesoporous silica submicrospheres for $\mathrm{Tl}(\mathrm{I})$ adsorption: Isotherm, kinetic and thermodynamic studies. J. Hazard. Mater. 371, 146-155 (2019).

6. Soltani, R., Shahvar, A., Gordan, H., Dinari, M. \& Saraji, M. Covalent triazine framework-decorated phenyl-functionalised SBA-15: Its synthesis and application as a novel nanoporous adsorbent. New J. Chem. 43, 13058-13067 (2019).

7. Marjani, A., Soltani, R., Pishnamazi, M., Rezakazemi, M. \& Shirazian, S. Functionalized pollen-like mesoporous silica for Cr(VI) removal. Microporous Mesoporous Mater. 310, 110531 (2021).

8. Soltani, R., Marjani, A., Soltani, R. \& Shirazian, S. Hierarchical multi-shell hollow micro-meso-macroporous silica for $\mathrm{Cr}(\mathrm{VI})$ adsorption. Sci. Rep. 10, 1-12 (2020).

9. Soltani, R., Marjani, A., Hosseini, M. \& Shirazian, S. Mesostructured hollow siliceous spheres for adsorption of dyes. Chem. Eng. Technol. 43, 392-402 (2020).

10. Soltani, R., Marjani, A., Moguei, M. R. S., Rostami, B. \& Shirazian, S. Novel diamino-functionalized fibrous silica submicro-spheres with a bimodal-micro-mesoporous network: Ultrasonic-assisted fabrication, characterization, and their application for superior uptake of Congo red. J. Mol. Liq. 294, 111617 (2019).

11. Soltani, R., Marjani, A., Hosseini, M. \& Shirazian, S. Synthesis and characterization of novel N-methylimidazolium-functionalized KCC-1: A highly efficient anion exchanger of hexavalent chromium. Chemosphere 239, 124735 (2020).

12. Soltani, R., Marjani, A. \& Shirazian, S. Shell-in-shell monodispersed triamine-functionalized $\mathrm{SiO}_{2}$ hollow microspheres with micro-mesostructured shells for highly efficient removal of heavy metals from aqueous solutions. J. Environ. Chem. Eng. 7, 102832 (2019).

13. Yanyan, L. et al. Removal of acetaminophen from synthetic wastewater in a fixed-bed column adsorption using low-cost-coconut shell waste pretreated with $\mathrm{NaOH}, \mathrm{HNO}$, ozone, and/or chitosan. J. Environ. Manag. 226, 365-376 (2018).

14. Yanyan, L., Kurniawan, T. A., Albadarin, A. B. \& Walker, G. Enhanced removal of acetaminophen from synthetic wastewater using multi-walled carbon nanotubes (MWCNTs) chemically modified with $\mathrm{NaOH}, \mathrm{HNO} / \mathrm{H} 2 \mathrm{SO} 4$, ozone, and/orchitosan. J. Mol. Liq. 251, 369-377 (2018).

15. Furukawa, H., Cordova, K. E., O’Keeffe, M. \& Yaghi, O. M. The chemistry and applications of metal-organic frameworks. Science 341,6149 (2013).

16. Madden, D. G. et al. Metal-organic material polymer coatings for enhanced gas sorption performance and hydrolytic stability under humid conditions. ACS Appl. Mater. Interfaces 12(30), 33759-33764 (2020).

17. Li, J. et al. Metal-organic framework-based materials: Superior adsorbents for the capture of toxic and radioactive metal ions. Chem. Soc. Rev. 47, 2322-2356 (2018).

18. Zhao, X. et al. Synergy effect of pore structure and amount of carboxyl site for effective removal of $\mathrm{Pb}^{2+}$ in metal-organic frameworks. J. Chem. Eng. Data 64, 2728-2735 (2019).

19. Feng, M., Zhang, P., Zhou, H. C. \& Sharma, V. K. Water-stable metal-organic frameworks for aqueous removal of heavy metals and radionuclides: A review. Chemosphere 209, 783-800 (2018).

20. Soltani, R., Marjani, A. \& Shirazian, S. A hierarchical LDH/MOF nanocomposite: Single, simultaneous and consecutive adsorption of a reactive dye and $\mathrm{Cr}(\mathrm{vi})$. Dalt. Trans. 49, 5323-5335 (2020).

21. Soltani, R., Shahvar, A., Dinari, M. \& Saraji, M. Environmentally-friendly and ultrasonic-assisted preparation of two-dimensional ultrathin $\mathrm{Ni} / \mathrm{Co}-\mathrm{NO}_{3}$ layered double hydroxide nanosheet for micro solid-phase extraction of phenolic acids from fruit juices. Ultrason. Sonochem. 40, 395-401 (2018). 
22. Zubair, M., Ihsanullah, I., Abdul Aziz, H., Azmier Ahmad, M. \& Al-Harthi, M. A. Sustainable wastewater treatment by biochar/ layered double hydroxide composites: Progress, challenges, and outlook. Bioresour. Technol. 319, 124128 (2021).

23. Yang, Q. et al. A water stable metal-organic framework with optimal features for $\mathrm{CO}_{2}$ capture. Angew. Chemie Int. Ed. 52, 1031610320 (2013).

24. Hao, J. N. \& Yan, B. A water-stable lanthanide-functionalized MOF as a highly selective and sensitive fluorescent probe for $\mathrm{Cd}^{2+}$. Chem. Commun. 51, 7737-7740 (2015).

25. Hua, W., Zhang, T., Wang, M., Zhu, Y. \& Wang, X. Hierarchically structural PAN/UiO-66-(COOH $)_{2}$ nanofibrous membranes for effective recovery of Terbium(III) and Europium(III) ions and their photoluminescence performances. Chem. Eng. J. 370, 729-741 (2019).

26. Thommes, M. et al. Physisorption of gases, with special reference to the evaluation of surface area and pore size distribution (IUPAC Technical Report). Pure Appl. Chem. 87, 1051-1069 (2015).

27. Li, R. et al. Large scale synthesis of NiCo layered double hydroxides for superior asymmetric electrochemical capacitor. Sci. Rep. 6, 18737 (2016).

28. Pelalak, R. et al. Molecular dynamics simulation of novel diamino-functionalized hollow mesosilica spheres for adsorption of dyes from synthetic wastewater. J. Mol. Liq. 322, 114812 (2021).

29. Soltani, R. et al. Preparation of COOH-KCC-1/polyamide 6 composite by in situ ring-opening polymerization: Synthesis, characterization, and Cd(II) adsorption study. J. Environ. Chem. Eng. 1, 104683. https://doi.org/10.1016/j.jece.2020.104683 (2020).

30. Glocheux, Y. et al. Adsorption study using optimised 3D organised mesoporous silica coated with Fe and $\mathrm{Al}$ oxides for specific $\mathrm{As}(\mathrm{III})$ and $\mathrm{As}(\mathrm{V})$ removal from contaminated synthetic groundwater. Microporous Mesoporous Mater. 198, 101-114 (2014).

31. Heydari, M., Jafari, M. T., Saraji, M., Soltani, R. \& Dinari, M. Covalent triazine-based framework-grafted functionalized fibrous silica sphere as a solid-phase microextraction coating for simultaneous determination of fenthionand chlorpyrifos by ion mobility spectrometry. Microchim. Acta 188(1) (2021).

32. Wu, J. et al. Efficient removal of metal contaminants by EDTA modified MOF from aqueous solutions. J. Colloid Interface Sci. 555, 403-412 (2019).

33. Ahmadijokani, F. et al. Superior chemical stability of UiO-66 metal-organic frameworks (MOFs) for selective dye adsorption. Chem. Eng. J. 399, 125346 (2020).

34. Foo, K. Y. \& Hameed, B. H. Insights into the modeling of adsorption isotherm systems. Chem. Eng. J. 156, 2-10 (2010).

35. Soltani, R., Marjani, A., Hosseini, M. \& Shirazian, S. Meso-architectured siliceous hollow quasi-capsule. J. Colloid Interface Sci. 570, 390-401 (2020).

36. Hall, K. R., Eagleton, L. C., Acrivos, A. \& Vermeulen, T. Pore- and solid-diffusion kinetics in fixed-bed adsorption under constantpattern conditions. Ind. Eng. Chem. Fundam. 5, 212-223 (1966).

37. Naushad, M., Ahamad, T. \& Al-Sheetan, K. M. Development of a polymeric nanocomposite as a high performance adsorbent for $\mathrm{Pb}(\mathrm{II})$ removal from water medium: Equilibrium, kinetic and antimicrobial activity. J. Hazard. Mater. 407, 124816 (2021).

38. Naushad, M., Alqadami, A. A. \& Ahamad, T. Removal of Cd(II) ion from aqueous environment using triaminotriethoxysilane grafted oxidized activated carbon synthesized via activation and subsequent silanization. Environ. Technol. Innov. 18, 100686 (2020).

39. Hasankola, Z. S., Rahimi, R. \& Safarifard, V. Rapid and efficient ultrasonic-assisted removal of lead(II) in water using two copperand zinc-based metal-organic frameworks. Inorg. Chem. Commun. 107, 107474 (2019).

40. Soltani, R., Dinari, M. \& Mohammadnezhad, G. Ultrasonic-assisted synthesis of novel nanocomposite of poly(vinyl alcohol) and amino-modified MCM-41: A green adsorbent for Cd(II) removal. Ultrason. Sonochem. 40, 533-542 (2018).

41. Kataria, N. \& Garg, V. K. Optimization of $\mathrm{Pb}$ (II) and Cd (II) adsorption onto ZnO nanoflowers using central composite design: Isotherms and kinetics modelling. J. Mol. Liq. 271, 228-239 (2018).

42. Lyu, F. et al. Efficient and fast removal of $\mathrm{Pb}^{2+}$ and $\mathrm{Cd}^{2+}$ from an aqueous solution using a chitosan/Mg-Al-layered double hydroxide nanocomposite. J. Colloid Interface Sci. 539, 184-193 (2019).

43. Yin, N., Wang, K., Xia, Y. \& Li, Z. Novel melamine modified metal-organic frameworks for remarkably high removal of heavy metal Pb (II). Desalination 430, 120-127 (2018).

44. Wang, K., Gu, J. \& Yin, N. Efficient removal of $\mathrm{Pb}(\mathrm{II})$ and $\mathrm{Cd}$ (II) using $\mathrm{NH} 2$-functionalized $\mathrm{Zr}$-MOFs via rapid microwavepromoted synthesis. Ind. Eng. Chem. Res. 56, 1880-1887 (2017).

45. Wang, Y. et al. Functionalized metal-organic framework as a new platform for efficient and selective removal of cadmium(II) from aqueous solution. J. Mater. Chem. A 3, 15292-15298 (2015).

46. Naushad, M. et al. Synthesis, characterization and application of curcumin formaldehyde resin for the removal of $\mathrm{Cd}^{2+}$ from wastewater: Kinetics, isotherms and thermodynamic studies. J. Ind. Eng. Chem. 29, 78-86 (2015).

47. Shahat, A. et al. Large-pore diameter nano-adsorbent and its application for rapid lead(II) detection and removal from aqueous media. Chem. Eng. J. 273, 286-295 (2015).

48. González, M. A., Pavlovic, I., Rojas-Delgado, R. \& Barriga, C. Removal of $\mathrm{Cu}^{2+}, \mathrm{Pb}^{2+}$ and $\mathrm{Cd}^{2+}$ by layered double hydroxide-humate hybrid Sorbate and sorbent comparative studies. Chem. Eng. J. 254, 605-611 (2014).

49. Heidari, A., Younesi, H. \& Mehraban, $\mathrm{Z}$. Removal of $\mathrm{Ni}(\mathrm{II}), \mathrm{Cd}(\mathrm{II})$, and $\mathrm{Pb}$ (II) from a ternary aqueous solution by amino functionalized mesoporous and nano mesoporous silica. Chem. Eng. J. 153, 70-79 (2009).

\section{Acknowledgements}

Saeed Shirazian acknowledges the supports by the Government of the Russian Federation (Act 211, contract 02.A03.21.0011) and by the Ministry of Science and Higher Education of Russia (Grant FENU-2020-0019).

\section{Author contributions}

R.S. conceived the idea of preparing $\mathrm{Ni}_{50} \mathrm{Co}_{50}-\mathrm{LDH}-\mathrm{COOH} / \mathrm{UiO}-66(\mathrm{Zr})-(\mathrm{COOH})_{2}$ nanocomposite material, designed the study on the synthesis of $\mathrm{Ni}_{50} \mathrm{Co}_{50}-\mathrm{LDH}-\mathrm{COOH} / \mathrm{UiO}-66(\mathrm{Zr})-(\mathrm{COOH})_{2}$ nanocomposite, synthesized and characterized the samples, conducted the adsorption studies, computed the theoretical adsorption data, analyzed the results, supervised the project, and wrote and edited the paper. R.P. and M.P. gathered experimental adsorption data, and validated the data. A.M. contributed to the final manuscript and also provided chemicals and laboratory equipment. A.B.A. and S.M.S. contributed to the adsorption analysis, the final manuscript preparation, and edited the paper. S.S. supervised the findings of this work, supervised the project, provided chemicals and laboratory equipment, and edited the paper. All authors verified the analytical methods.

\section{Competing interests}

The authors declare no competing interests. 


\section{Additional information}

Correspondence and requests for materials should be addressed to A.M.

Reprints and permissions information is available at www.nature.com/reprints.

Publisher's note Springer Nature remains neutral with regard to jurisdictional claims in published maps and institutional affiliations.

(c) (1) Open Access This article is licensed under a Creative Commons Attribution 4.0 International License, which permits use, sharing, adaptation, distribution and reproduction in any medium or format, as long as you give appropriate credit to the original author(s) and the source, provide a link to the Creative Commons licence, and indicate if changes were made. The images or other third party material in this article are included in the article's Creative Commons licence, unless indicated otherwise in a credit line to the material. If material is not included in the article's Creative Commons licence and your intended use is not permitted by statutory regulation or exceeds the permitted use, you will need to obtain permission directly from the copyright holder. To view a copy of this licence, visit http://creativecommons.org/licenses/by/4.0/.

(C) The Author(s) 2021 